\title{
Determinantes del periodo medio de pago municipal y eficacia del principio de sostenibilidad de la deuda comercial
}

\author{
Jorge Olmo $^{a}$, Isabel Brusca ${ }^{\mathrm{b}}$ \\ a,b) Departamento de Contabilidad y Finanzas, Universidad de Zaragoza. Facultad de Economía y Empresa. Zaragoza, España.
}

\author{
${ }^{a}$ Corresponding author. \\ E-mail address: jorgolmo@unizar.es
}

\section{A R T I C L E I N F O}

Article history:

Received 29 March 2019

Accepted 2 September 2019

Available online 1 January 2021

\section{Códigos JEL:}

Códig
H71
H72

$\mathrm{H} 63$

Palabras clave

Entidades Locales

Disciplina presupuestaria

Condición financiera

Liquidez

Sostenibilidad

\section{R E S U M E N}

Las medidas implantadas para mejorar la liquidez de los municipios españoles y el principio de sostenibilidad de la deuda comercial ponen de manifiesto la importancia de controlar la morosidad pública. En este contexto, este trabajo comprueba el efecto de la regla fiscal que controla los plazos de pago y si el entorno político, socioeconómico y presupuestario incide en el periodo de pago de los ayuntamientos españoles. Para ello, se realiza un análisis exploratorio y se aplica la metodología de datos de panel (2009-2015). Los resultados contribuyen a demostrar la eficacia del control del periodo de pago y evidenciar los factores de riesgo en la situación financiera a corto plazo.

(C)2021 ASEPUC. Published by EDITUM - Universidad de Murcia. This is an open access article under the CC BY-NC-ND license (http://creativecommons.org/licenses/by-nc-nd/4.0/).

Determinants of the municipal average payment period and effectiveness of the commercial debt sustainability principle

A B S T R A C T

The policies implemented to improve the liquidity of Spanish municipalities and the introduction of the commercial debt sustainability principle reveal the importance of controlling late payment by public sector. In this context, the purpose of this paper is to analyse the effect of the fiscal rule directed to control the average payment periods of public administrations and whether the political environment, socioeconomic characteristics and financial situation influence on the average payment period of municipalities. In order to achieve this goal, an exploratory analysis is carried oud and panel data methodology (2009-2015) is applied. The paper contributes to provide evidence of the effectiveness of the commercial debt sustainability principle and improves the knowledge for the analysis of short-term financial position.

(C2021 ASEPUC. Publicado por EDITUM - Universidad de Murcia. Este es un artículo Open Access bajo la licencia CC BY-NC-ND (http://creativecommons.org/licenses/by-nc-nd/4.0/). 


\section{Introduction}

En un contexto económico marcado por la crisis global, en 2011 la situación de la mayoría de los ayuntamientos españoles se caracterizaba por falta de liquidez, retrasos en el pago a proveedores, acumulación de déficits presupuestarios y sucesión de remanentes de tesorería negativos (Algarra \& Romea, 2015). En ese marco, se promulgan en España una serie de reformas con el objetivo de poner freno al déficit público y erradicar los problemas de morosidad de las administraciones públicas.

Primero, en septiembre de 2011 se consagra constitucionalmente el principio de estabilidad presupuestaria y las previsiones sobre los límites de déficit y deuda pública. Posteriormente, la Ley Orgánica 2/2012 de Estabilidad Presupuestaria y Sostenibilidad Financiera (LOEPSF) instrumenta los límites de déficit, deuda y gasto público. Al año siguiente, se modifica la ley de estabilidad para introducir el principio de sostenibilidad de la deuda comercial, por lo que se expande el ámbito de aplicación de la normativa de estabilidad no solo a la deuda financiera sino también a la deuda comercial (Medina, 2014).

Por parte del gobierno también se impulsan una serie de políticas con la finalidad de favorecer la liquidez de las administraciones. En particular, el Fondo para la financiación de los pagos a proveedores (FFPP) es la medida financiera más relevante, ya que supone una importante inyección de liquidez a las administraciones públicas con el objetivo de saldar parte de la deuda comercial en 2012 y 2013. Además, paralelamente se llevan a cabo modificaciones en la normativa de morosidad en lo relativo a los plazos legales de pago del sector público. Brusca \& Olmo (2018) manifiestan que la situación financiera a corto plazo de las administraciones públicas cobra más transcendencia debido a las diferentes reformas y políticas aplicadas en este ámbito.

Ante este escenario económico y como consecuencia de la implantación de las diversas medidas públicas en el marco de lucha contra la morosidad, resulta necesario seguir avanzando en el análisis de la liquidez del sector local español, objetivo de este trabajo. Para ello, se utiliza como variable de referencia el periodo medio de pago a acreedores, que refleja los días que por término medio tardan los ayuntamientos en pagar a sus acreedores comerciales las deudas derivadas de la ejecución del gasto en bienes corrientes y servicios e inversión. La orden EHA/4041/2004, de 23 de noviembre, por la que se aprueba la Instrucción del Modelo normal de Contabilidad Local, vigente hasta el 1 de enero de 2015, calcula este indicador como el cociente de las obligaciones pendientes de pago y las obligaciones reconocidas netas de ese tipo de operaciones, multiplicado por 365.

En concreto, para alcanzar el objetivo inicialmente se realiza un análisis exploratorio con la intención de reflejar la evolución del periodo medio de pago, atendiendo al hecho de si los municipios han participado o no en las diferentes medidas financieras que pretendían reducir la morosidad. Posteriormente, a través de estimaciones dinámicas de datos panel, se analiza el efecto que tiene el principio de sostenibilidad de la deuda comercial y la influencia de las características políticas, socioeconómicas y presupuestarias en el periodo de pago de los ayuntamientos. En este contraste se aplica el Método Generalizado de Momentos (GMM), utilizando estimaciones en diferencias (Arellano \& Bond, 1991) y estimaciones en niveles y diferencias (Blundell \& Bond, 1998), en una muestra que prescinde de los municipios que participaron en las medidas financieras para mejorar la liquidez de los ayuntamientos.
Desde un punto de vista global, hay evidencia previa en la literatura que soporta que los ayuntamientos con plazos de pago más elevados fueron los que mayoritariamente participaron en el FFPP, así como la reducción de los plazos de pago en 2014 como consecuencia de la introducción del principio de sostenibilidad de la deuda comercial en la normativa española (Olmo, Brusca \& Labrador, 2018). Contribuyendo en esta línea, la presente investigación se caracteriza por excluir a las entidades locales que han sido beneficiarias de los diferentes incentivos económicos para favorecer la liquidez, ya que su inclusión podría ocasionar un factor de sesgo en el análisis de la situación financiera a corto plazo. Además, la aplicación de modelos dinámicos de datos de panel corrige la inconsistencia de los modelos estáticos (Arellano \& Bond, 1991), que conlleva a un mayor rigor de los resultados obtenidos.

Este estudio constituye un avance sobre los trabajos realizados previamente en esta área (Brusca \& Olmo, 2018; Olmo et al., 2018). Desde el punto de vista metodológico se aplica una metodología más robusta, se plantean nuevas hipótesis de contraste, entre las que figuran factores socioeconómicos y se analiza un horizonte temporal más amplio que permite comprobar el efecto del principio de sostenibilidad de deuda comercial en los dos primeros años de aplicación.

Respecto al marco teórico, este trabajo complementa los estudios previos que examinan la condición financiera de las organizaciones, aunque se centra en particular en el análisis de la situación financiera a corto plazo. Wang (2014) expresa que el análisis de la condición financiera puede centrarse en una única dimensión. Por otra parte, este planteamiento también tiene cabida en el marco teórico del federalismo fiscal, en el que hay investigaciones previas que analizan la eficacia de las limitaciones de las normas fiscales en la deuda (Kiewiet \& Szakaly, 1996) y la influencia de los factores del entorno en la situación financiera local (Bastida \& Benito, 2005).

Por lo tanto, este estudio contribuye en el análisis de la liquidez de las administraciones públicas, dimensión financiera que ha pasado más desapercibida. Saura (2013) destaca que el incumplimiento de los plazos de pago por parte de las entidades locales se configura como un indicador inequívoco de la situación financiera de las mismas, por lo que el periodo medio de pago es una de las variables clave para controlar y asegurar la sostenibilidad de las finanzas locales.

Este trabajo se estructura del siguiente modo: en la siguiente sección se hace referencia a la literatura previa y se plantean las hipótesis que se pretenden contrastar. Posteriormente, en el tercer apartado se realiza una síntesis de las reformas introducidas en el ámbito de la disciplina de pago y de lucha contra la morosidad pública. En la cuarta sección se delimita la muestra, se especifican las variables y se describe la metodología. El quinto apartado se dedica al análisis y discusión de los resultados. Por último, en la sexta sección se incluyen las conclusiones finales.

\section{Marco teórico}

El análisis de la condición financiera consiste en evaluar la salud financiera de una organización con el fin último de identificar los factores que impactan en la condición financiera y proporcionar recomendaciones con el objetivo de mejorarla (Wang, 2014). En la literatura figuran múltiples definiciones y diferentes medidas de salud financiera (PlataDíaz, Pérez-López \& Zafra-Gómez, 2012), sin embargo, la mayoría de los trabajos sostienen la idea de que la condición financiera está formada por diferentes dimensiones. Groves, Godsey \& Shulman (1981) definen este concepto con- 
siderando cuatro dimensiones: cash solvency, budgetary solvency, long-run solvency y service level solvency, dimensiones que también tiene presente la International City/County Management Association (ICMA) (Groves, Godsey \& Shulman, 2003). Otros estudios aplicados al ámbito local español evalúan la condición financiera atendiendo a la liquidez y a la solvencia presupuestaria (flexibilidad, independencia y sostenibilidad) (Zafra-Gómez, López-Hernández \& HernándezBastida, 2009a, 2009b, 2009c).

Como el objetivo de este trabajo consiste en analizar específicamente la dimensión de liquidez, desde el punto de vista legal la LOEPSF determina que existe sostenibilidad de la deuda comercial cuando el periodo medio de pago a los proveedores no supera el plazo máximo de 30 días. Anteriormente, Groves et al. (2003) definen la liquidez como la habilidad que tienen las entidades de generar suficiente efectivo y cumplir con sus obligaciones a corto plazo, por lo que en definitiva, los coeficientes de liquidez miden la capacidad de un gobierno para pagar sus cuentas, es decir, que un gobierno tenga suficiente dinero para afrontar sus facturas (Bowman \& Calia, 1997).

Asimismo, la literatura destaca algunos aspectos relacionados con esta dimensión que evidencian dificultades financieras de las entidades. Una de las señales de alerta temprana que establece la Advisory Commission on Intergovernmental Relations (ACIR), se basa en el incremento de la deuda a corto plazo al cierre del ejercicio o de las facturas impagadas (ACIR, 1973). Kloha, Weissert \& Kleine (2005) entienden que el "fiscal distress"tiene consideraciones a largo plazo y a corto plazo, y en este segundo caso se puede identificar con la obligación de efectuar los pagos a su debido tiempo.

En este aspecto, el riesgo de liquidez surge en el momento que no hay suficientes activos líquidos disponibles o cuando no están disponibles inmediatamente para cumplir con las obligaciones (Williams, 2013). Además, en algunas de las definiciones dadas al concepto de condición financiera también se tiene presente esta dimensión, como por ejemplo cuando el Governmental Accounting Standards Board (GASB) hace alusión a los cambios sufridos en las posiciones de tesorería (GASB, 1999) o cuando se valora el hecho de la puntualidad en el pago de las obligaciones (Wang, Dennis \& Sen, 2007).

En el caso español, considerando como principal referente la participación de los ayuntamientos en el Fondo para la financiación de los pagos a proveedores, se demuestra la relevancia que tiene la ejecución del ahorro bruto, la carga financiera, el gasto corriente y el periodo de cobro en la morosidad de los ayuntamientos (Brusca \& Olmo, 2018). Balaguer-Coll e Ivanova-Toneva (2019) encuentran que cumplir con el límite de pago de 30 días repercute en un menor endeudamiento local, circunstancia que permite evitar los intereses por retrasos en los pagos.

También desde un enfoque profesional resulta esencial administrar correctamente la tesorería de los ayuntamientos. En la gestión de las finanzas públicas se diferencian e interactúan las actividades de la gestión de la deuda pública y la gestión de tesorería. La gestión de tesorería tiene una perspectiva relativamente a corto plazo, en cambio, la gestión de la deuda tiene un horizonte de medio y largo plazo (Gardner \& Olden, 2013). Mientras la gestión de la deuda se centra principalmente en la composición de la cartera de deuda con la intención de mejorar la adaptación ante los choques económicos (Williams, 2013), la gestión de tesorería es la estrategia y los procesos asociados para gestionar de manera rentable el corto plazo: flujos de efectivo y los saldos de efectivo del gobierno (Williams, 2004). Por lo tanto, hacer un "buen uso" de la deuda comercial permite a los municipios obtener más rendimiento de sus posiciones de tesorería.

Asimismo, las medidas adoptadas para controlar la situación financiera tienen un efecto importante en la gestión de las finanzas públicas (López-Hernández, Zafra-Gómez \& Ortiz-Rodríguez, 2012). Por un lado, la Teoría del urbanismo de austeridad defiende que el efecto de la Gran Recesión supone una transformación neoliberal de los gobiernos locales en máquinas de austeridad que se caracteriza por la unión de intereses privados y financieros, reducción de los servicios públicos y del empleo público (Donald, Glasmeier, Gray \& Lobao, 2014). Por otro lado, con un enfoque más amplio, la Teoría del municipalismo pragmático sostiene que los gobiernos locales afrontan la austeridad innovando y explorando prestaciones alternativas de servicios públicos, dentro de los límites políticos y las necesidades de la comunidad (Kim \& Warner, 2016). La eficiencia en costes que podría traer consigo la adopción de modalidades de gestión de servicios públicos alternativas en los ayuntamientos españoles dependen en gran medida del escenario económico y de la situación financiera de la entidad (Pérez-López, Prior, Zafra-Gómez, 2015).

En un entorno de crisis, el control de la liquidez de las administraciones públicas es fundamental, lo que puede motivar la aplicación de diversas medidas por parte de los gobiernos locales españoles, inmersos en un contexto de reforma contable que ha requerido de diversos cambios institucionales (Fresneda Fuentes \& Hernández Borreguero, 2018). Por tanto, si los controles presupuestarios preexistentes controlan fiscalmente la deuda financiera, el principio de sostenibilidad de deuda comercial aspira a evitar el uso abusivo de la deuda comercial mediante el control de los plazos de pago.

A este respecto, la literatura del federalismo fiscal analiza el impacto de determinadas políticas fiscales. En particular, a este marco teórico pertenecen una serie trabajos que pretenden comprobar la eficacia de los límites de deuda (Kiewiet \& Szakaly, 1996; Pogue, 1970), siendo muy habitual el uso de la metodología de datos de panel (Benito, Guillamón \& Bastida, 2015; Cabasés, Pascual \& Vallés, 2007). Los estudios previos revelan que los límites fiscales establecidos suelen tener más éxito si la norma deriva de la constitución (Pogue, 1970) o si se utiliza el referéndum en su aprobación (Kiewiet \& Szakaly, 1996).

En lo relativo al contexto local español diferentes investigaciones constatan la repercusión de la Ley reguladora de las Haciendas Locales en el endeudamiento (Cabasés et al., 2007; Vallés, Pascual \& Cabasés, 2003) y los efectos de las leyes de estabilidad presupuestaria en la situación financiera (Brusca, Labrador \& Montesinos, 2015a; Olmo, 2018; Vicente, Ríos \& Guillamón, 2013). Desde otra perspectiva, también se evidencia la importancia que tiene disponer de un mayor control interno en el ayuntamiento para controlar la deuda local (Gras, Hernández \& Palacios, 2014).

Respecto a la eficacia de los límites legales de deuda, Vallés et al. (2003) mediante modelos de datos de panel evidencian la eficacia que tiene el límite sobre el uso de la deuda regulado en la normativa de Haciendas Locales. Vila (2012) muestra que los gobiernos locales conservadores presentan un nivel de incumplimiento de los límites mayor que los partidos de izquierda, fundamentalmente debido a los planes de inversión.

También, se constata que la anterior normativa de estabilidad presupuestaria favorece el control de endeudamiento (Benito et al., 2015; Vicente et al., 2013), a pesar de que existe una gran mayoría de municipios que sobrepasan los límites de deuda regulados en la normativa de Haciendas Locales (Benito et al., 2015). Vicente et al. (2013) confirman que la normativa de estabilidad de 2001 evitó la creación Ci- 
clos Políticos Presupuestarios en el endeudamiento, aunque no redujo la manipulación por parte de los políticos en el déficit, gasto de capital o gasto corriente.

Teniendo presente lo anterior, como las normas fiscales son una herramienta que los encargados de formular las políticas aplican para "atar sus propias manos" (Benito et al., 2015), en principio, se espera que sean eficaces. Por ello entendiendo que la introducción del principio de sostenibilidad favorece el control del periodo medio de pago de los ayuntamientos, se plantea la siguiente hipótesis

H1: Existe una relación negativa entre la aplicación del principio de sostenibilidad de deuda comercial y el periodo medio de pago a proveedores.

La literatura también trata de comprobar la influencia que tienen los factores políticos en las finanzas locales. Para el contexto local español, investigaciones previas evalúan la posible repercusión de las características políticas en el endeudamiento (Guillamón, Benito \& Bastida, 2011), presión fiscal (Benito, Bastida \& Muñoz, 2010), gasto público (Bastida, Benito \& Guillamón, 2009) o la sostenibilidad financiera (Rodríguez-Bolívar, Navarro-Galera, López-Subirés \& Alcaide Muñoz, 2018).

Otros trabajos que analizan los determinantes políticos tienen presente las diferentes dimensiones de la condición financiera (Cabaleiro-Casal, Buch-Gómez \& Vaamonde, 2014; García-Sánchez, Mordan \& Prado-Lorenzo, 2012b) o se orientan con la finalidad de demostrar la existencia de posibles Ciclos Políticos Presupuestarios (Brusca et al., 2015a; Benito, Bastida \& Vicente, 2012; Vicente et al., 2013).

En concreto, respecto a la influencia de la ideología política en la situación financiera, Cusack (1997) define este fenómeno con la manifestación de que "el partido político importa", refiriéndose en concreto a las políticas de gasto más elevadas de los gobiernos progresistas. La mayoría de los trabajos parten de la hipótesis de que los gobiernos de tendencia progresista tienden a favorecer el gasto público o el nivel de deuda, mientras que los partidos conservadores ejecutan políticas públicas más ahorradoras (Kiewiet \& Szakaly 1996; Tellier, 2006). Sin embargo, también hay investigaciones que no encuentran relación significativa entre la ideología política del gobierno local y la situación financiera (Abizadeh \& Gray, 1993; Bastida \& Benito, 2005; Benito \& Bastida, 2004; Guillamón et al., 2011). Incluso los partidos políticos que no tienen definida la ideología política pueden llevar a cabo una mejor gestión de la liquidez y del endeudamiento local (Cabaleiro-Casal et al., 2014). Benito \& Bastida (2008) encuentran que la ideología política tiene un pequeño impacto en el resultado presupuestario no financiero, pero no influye ni en el gasto total y ni en los ingresos por impuestos.

De todas maneras, en cierto grado los resultados previos soportan la idea de que los gobiernos conservadores tienden a racionalizar el gasto, presentan mejor situación financiera o recurren a un menor endeudamiento. García-Sánchez et al. (2012b) constatan la influencia negativa que tienen los gobiernos de izquierdas en el índice de ahorro neto, la dimensión de solvencia a corto plazo, el nivel de solvencia de servicios públicos y en el índice de ingresos fiscales. Tomando como referencia los pronunciamientos de Basilea II, a través de un modelo logit de datos de panel se confirma que los gobiernos de izquierdas tienen mayor riesgo de impago bancario (Navarro-Galera, Buendía-Carrillo, Lara-Rubio \& RayoCantón, 2017). Rodríguez-Bolívar et al. (2018) corroboran que los gobiernos de izquierdas son más sensibles a las presiones de los ciudadanos para incrementar el gasto social, repercutiendo esta circunstancia negativamente en la sosteni- bilidad financiera.

Por tanto, como los gobiernos de izquierdas de los municipios españoles presentan peor situación de endeudamiento financiero (Brusca, Manes-Rossi \& Aversano, 2015b, GarcíaSánchez, Prado-Lorenzo \& Cuadrado-Ballesteros, 2011), y a partir del planteamiento de Cusack (1997), se plantea $H 2$ en el sentido de que los que gobiernos conservadores pueden afrontar de una forma más puntual las obligaciones de pago con sus proveedores.

H2: Existe una relación positiva entre los ayuntamientos progresistas y el periodo medio de pago a proveedores.

La literatura previa también ha analizado si el nivel de concentración política influye en las finanzas locales. Por un lado, se hace alusión a la "hipótesis Roubini y Sachs del gobierno débil" (RSH) que significa que mayor fragmentación deriva en más gasto público, en déficits elevados y en más deuda (Roubini \& Sachs, 1989). Borge (1995) se pronuncia teóricamente en base a las peticiones que ejercen los diferentes grupos de interés de la sociedad noruega, por lo que un gobierno fuerte permite negarse a las demandas de los grupos minoritarios, de ahí que el crecimiento de gasto se vea reducido. Ashworth, Geys \& Heyndels (2005) manifiestan que los gobiernos fragmentados se demorarán a la hora de adoptar políticas fiscales, lo que implica un aumento del déficit y que la deuda es inferior en los gobiernos unipartidistas en intervalos de tiempo pequeños.

Por otro lado, una argumentación opuesta procede del poder que pueden ostentar los "actores del veto" sobre algunas decisiones políticas (Tsebelis, 1995). De acuerdo con esta idea, la formación de una coalición de gobierno puede ser útil desde el punto de vista de que hay otro partido que controla y supervisa las acciones llevadas a cabo por el partido que está en el poder (Rodríguez-Bolívar et al., 2018).

En el caso de las entidades locales españolas se encuentran resultados que demuestran que los gobiernos con mayor fragmentación política recurren a un menor gasto (Bastida et al., 2009) y acumulan menos deuda (Guillamón et al., 2011; Olmo, 2018; Pérez-López, Plata-Díaz, Zafra-Gómez \& LópezHernández, 2013).

Sin embargo, hay hallazgos que confirman la hipótesis de RSH (Balaguer-Coll \& Ivanova-Toneva, 2019; CabaleiroCasal et al., 2014) o no constatan la relación significativa entre la fortaleza del gobierno y el endeudamiento (PérezLópez, Plata-Díaz, Zafra-Gómez \& López-Hernández, 2014). Benito et al. (2012) ponen de manifiesto que los gobiernos en mayoría absoluta cobran una mayor cantidad de impuestos, aunque no confirman la significatividad de esta variable con el nivel de gasto. Tal como manifiestan Balaguer-Coll e Ivanova-Toneva (2019), no existe consenso pleno sobre el efecto de la fortaleza política en la situación financiera, de ahí que se considere conveniente plantear $\mathrm{H} 3$ de la siguiente manera:

H3: Existe una relación negativa/positiva entre los ayuntamientos gobernados bajo coaliciones políticas y el periodo medio de pago a proveedores.

Las dos hipótesis siguientes comprueban si las características socioeconómicas de la entidad local pueden tener influencia en el periodo medio de pago de los ayuntamientos.

Estas dos hipótesis que consideran la tasa de desempleo y la tasa de inmigración contribuyen en el marco de trabajos previos que verifican la influencia de los factores socioeconómicos, en otros aspectos, en la situación financiera local (Guillamón et al., 2011; Rodríguez-Bolívar, Navarro-Galera, Alcaide-Muñoz \& López-Subires, 2016a).

Mediante la tasa de desempleo se pretende analizar si las 
circunstancias laborales de la población del municipio repercuten en la situación financiera a corto plazo. Kloha et al. (2005) manifiestan la relación perjudicial que supone el desempleo en la generación de "fiscal distress". También hay evidencia previa que soporta que incrementos de la tasa de paro implican un aumento de los déficits, que a largo plazo llevaría a una mayor deuda (Feld \& Kirchgässner, 2001). De la misma manera, para el contexto local español hay resultados que permiten afirmar la influencia desfavorable del desempleo en los niveles de déficit, deuda, gastos de capital y gasto corriente (Vicente et al., 2013). Si los ayuntamientos se desenvuelven en un entorno con una delicada situación de desempleo, posiblemente se vean en la obligación de incrementar la presión fiscal sobre sus ciudadanos (Benito et al., 2010). En vistas a que el desempleo afecta de manera desfavorable en la sostenibilidad financiera (Rodríguez-Bolívar, Navarro-Galera, Alcaide-Muñoz \& López-Subires, 2016b), en este caso, también se espera que incida desfavorablemente en la sostenibilidad de la deuda comercial, por lo que se define H4 en la siguiente dirección:

H4: Existe una relación positiva entre la tasa de desempleo local y el periodo medio de pago a proveedores.

El estudio de la tasa de inmigración pretende analizar la incidencia de las características de la población de las regiones. Trabajos previos encuentran que los flujos migratorios o la tasa de inmigración pueden incrementar el endeudamiento (Bruce, 1995; Olmo, 2018; Vicente et al., 2013) o debilitar la sostenibilidad financiera (Rodríguez-Bolívar et al., 2016a). Por tanto, independientemente de que los municipios con más inmigración traten de obtener mayores niveles de ingresos, éstos también se ven en la obligación de desembolsar un mayor gasto corriente para atender las necesidades de sus ciudadanos y ofrecer una mayor demanda de servicios (Zafra-Gómez et al., 2009c). De acuerdo con lo anterior, se comprueba si la tasa de inmigración influye significativamente en la liquidez municipal:

H5: Existe una relación positiva entre la tasa de inmigración del municipio y el periodo medio de pago a proveedores.

Posteriormente, se analizan diferentes aspectos de la condición financiera. Para ello, se comprueba la política de cobro (periodo medio de cobro), la influencia de las fuentes de financiación no financieras (autonomía fiscal y dependencia de las transferencias) y la situación financiera a largo plazo (relevancia de la carga financiera).

Respecto al periodo medio de cobro, hay que tener en cuenta que el periodo de cobro se caracteriza por el cobro de impuestos en períodos muy concretos, por lo que es más irregular que el periodo de pago de los ayuntamientos. Con este indicador, además de saber el plazo medio de cobro de los impuestos y tasas, nos da una idea de la eficacia recaudadora y de la disciplina fiscal de los ciudadanos (Mabras, 2011). Trabajos previos incorporan el periodo de cobro cuando analizan la dimensión de liquidez (Turley, Robbins \& Mcnena, 2015). Brusca \& Olmo (2018) plantean que los municipios que cobran sus derechos de crédito más tarde tienen mayor probabilidad de demorar sus deudas con proveedores. En base a lo anterior, H6 se presenta de la siguiente manera:

H6: Existe una relación positiva entre el periodo medio cobro y el periodo medio de pago a proveedores.

La autonomía fiscal es una medida que refleja el grado de autonomía que tiene la entidad local sin depender del gobierno central (Turley et al., 2015), por lo tanto, el hecho que un municipio tenga mayor autosuficiencia y control directo sobre sus recursos fiscales son aspectos positivos para la salud financiera de la entidad. Presentar mayor índice de autonomía financiera también afecta positivamente a la dimensión de solvencia presupuestaria (Bisogno, Cuadrado-Ballesteros, Santis \& Citro, 2019), sin embargo, puede ser un aspecto que sea percibido negativamente por los ciudadanos motivado porque puede implicar una presión fiscal más elevada (Benito et al., 2010). Trabajos previos encuentran que la autonomía financiera limita la necesidad de deuda (Benito \& Bastida, 2004; Pérez-López et al., 2014), aunque también puede darse el caso contrario al existir una mayor capacidad para hacer frente a la carga financiera (Vallés et al., 2003). Además, a través de diferentes medidas de independencia financiera, las investigaciones que evalúan la condición financiera local tienen presente la importancia de esta característica con su inclusión en los modelos operativos (García-Sánchez, CuadradoBallesteros, Frías-Aceituno \& Mordan, 2012a; Zafra-Gómez et al., 2009a). Navarro-Galera, Rodríguez-Bolívar, AlcaideMuñoz \& López-Subires (2016) afirman que la naturaleza y origen de los ingresos repercute en la sostenibilidad financiera. Como la autonomía financiera permite mayor control y disponibilidad sobre los recursos propios, se entiende que la misma favorece el abono de las deudas con los proveedores:

H7: Existe una relación negativa entre la autonomía financiera y el periodo medio de pago a proveedores.

$\mathrm{El}$ ratio de dependencia financiera es la medida opuesta a la autonomía (Turley et al., 2015). Cohen, Costanzo \& ManesRossi (2017) expresan que mayores subsidios per cápita son un síntoma de vulnerabilidad, principalmente ante cambios de políticas por parte del gobierno central. En la literatura existe cierto debate sobre el efecto de las transferencias recibidas, ya que se demuestra que en ocasiones el uso de las mismas conlleva un incremento del gasto y del déficit público (Levaggi \& Zanola, 2003). Esta circunstancia tiene conexión con el posible impacto que tienen las transferencias en el nivel de gasto municipal. El flypaper effect se refiere a que el gasto público es más sensible ante cambios en las subvenciones que ante cambios en los ingresos propios y por lo tanto ante estas modificaciones los gobiernos reaccionan asimétricamente (Heyndels, 2001). Este efecto ha sido analizado para las entidades locales españolas ya que se constata que se realiza un gasto más elevado en las variaciones de transferencias que ante variaciones de ingresos propios (Bastida et al., 2009). Por lo tanto, el hecho de que el gasto público municipal sea más sensible ante los recursos que provienen de las transferencias, así como de la incertidumbre derivada del momento de cobro o la posible retención o reducción de las mismas, hace pensar que mayor dependencia financiera no es un aspecto que contribuya en la celeridad del abono de las deudas con los proveedores:

H8: Existe una relación positiva entre la dependencia de las subvenciones y el periodo medio de pago a proveedores.

En último lugar, a través de la carga financiera, se analiza el efecto de la situación financiera a largo plazo (Brusca et al., 2015b). La literatura de predicción de dificultades financieras incluye la carga financiera por habitante para medir la salud fiscal municipal (García-Sánchez et al., 2012a). De acuerdo con las dimensiones de la condición financiera, la dimensión de solvencia a largo plazo tiene una relación estadísticamente significativa con la dimensión de liquidez y la solvencia presupuestaria (Wang et al., 2007). Sin embargo, se debe advertir que conforme se destinan más recursos a sufragar las obligaciones financieras a largo plazo y los intereses financieros se reduce la flexibilidad financiera del gobierno local (Rivenbark, Roenigk \& Allison, 2010). El coeficiente de liquidez de los gobiernos locales americanos tiene una corre- 
lación negativa con la deuda por habitante, a diferencia de lo que sucede con la variación de ingresos y el crecimiento poblacional (Gore, 2009).

Balaguer-Coll e Ivanova-Toneva (2019) indican que si las entidades locales realizan sus pagos comerciales en el tiempo legalmente establecido, evitan la generación de intereses que podrían suponer un aumento del endeudamiento. Asimismo, afrontar mayores desembolsos como consecuencia de la inversión local también repercute en más endeudamiento (Olmo, 2018; Vallés et al., 2003), con el inconveniente que supone que la deuda a largo no influye significativamente en la eficiencia en costes de servicios públicos, a diferencia de lo que sucede con la deuda comercial (Prior, Martín-PinillosCastellanos, Pérez-López \& Zafra-Gómez, 2019). De acuerdo con lo anterior, el hecho de que un ayuntamiento cuente con menor flexibilidad financiera y deba afrontar mayor deuda a largo plazo derivada de los proyectos de inversión, podría generar más retrasos en las obligaciones de pago con los proveedores por lo que se plantea $H 9$ de la siguiente manera:

H9: Existe una relación positiva entre la carga financiera y el periodo medio de pago a proveedores.

\section{Políticas implantadas para controlar la deuda y la morosidad del sector público}

Los problemas de morosidad de las entidades locales comienzan a reflejarse a partir del 2007. La situación de iliquidez del sector local español es motivada por la incapacidad de generación de ahorro que es consecuencia de la caída de ingresos tributarios y la acumulación de obligaciones pendientes de pago (Bellod, 2014). Para paliar esta situación, en 2009 se efectúa un primer intento de reducir la deuda comercial de los ayuntamientos, permitiendo a las entidades locales endeudarse para el pago de facturas atrasadas, a través de los dispuesto en el Real-Decreto Ley 5/2009 de medidas extraordinarias y urgentes para facilitar a las Entidades Locales el saneamiento de deudas pendientes de pago con empresas y autónomos. Esta primera medida, que tiene la finalidad de sanear parte de las deudas pendientes de pago con empresas y autónomos, se acogen alrededor del $5 \%$ de los municipios, en concreto 438 ayuntamientos, por un importe global de 2.322 millones de euros (Saura, 2013).

Debido al aumento de impagos, retrasos y prórrogas en las liquidaciones de las facturas vencidas, se publica la Ley 15/2010 de medidas de lucha contra la morosidad de las operaciones comerciales, legislación que como norma general reduce a 30 días el plazo máximo de pago del sector público (efectivo desde el 1 de enero de 2013). También se propone un procedimiento efectivo y ágil para hacer efectivas las deudas de los poderes públicos y se establecen mecanismos de transparencia en materia de cumplimiento de las obligaciones de pago, a través de informes periódicos a todos niveles de administración (Pascual-Ezama \& del Río, 2012). Esta modificación en el marco jurídico de los plazos legales de pago, se produce en España un año antes que la publicación de la Directiva 2011/7/UE que es la norma comunitaria que establece las medidas de lucha contra la morosidad en las operaciones comerciales que tiene el objetivo de fortalecer el pago de las facturas a tiempo, por parte de empresas y administraciones públicas.

En el ámbito fiscal y presupuestario de la UE también suceden reformas importantes, como por ejemplo los pronunciamientos que emanan de las medidas acordadas en el Consejo Europeo de 24 y 25 de marzo de 2011 (Six Pack), el Tratado de Estabilidad, Coordinación y Gobernanza en la Unión
Económica y Monetaria de 2 de marzo de 2012 y la aprobación de dos reglamentos el 21 de mayo de 2013 sobre supervisión presupuestaria (Two Pack). La promulgación de este elenco de medidas trata de reforzar la idea de estabilidad presupuestaria de la UE, promover la disciplina presupuestaria, incrementar la evaluación y vigilancia de los presupuestos y reforzar los procedimientos de control.

En consecuencia, el marco fiscal español se ve afectado por esta serie de reformas. En 2011 se modifica el artículo 135 de la Constitución con el propósito de consagrar el principio de estabilidad presupuestaria y el límite de deuda pública en la Constitución Española. Posteriormente, para desarrollar este precepto se publica en 2012 la LOEPSF, normativa más exigente y rigurosa que la normativa europea, tanto en los límites a alcanzar como en el régimen transitorio (López-Díaz \& Morán, 2013).

En lo que respecta a las medidas financieras para mejorar la liquidez, en 2012 tiene lugar la primera de las tres fases del FFPP que se constituye con la finalidad de abonar parte de las obligaciones pendientes de pago de los ayuntamientos. La primera fase del FFPP está regulada en el Real Decreto 4/2012 por el que se determinan las obligaciones de información y procedimientos necesarios para establecer un mecanismo de financiación para el pago a los proveedores de las entidades locales y en el Real Decreto 7/2012 por el que se crea el Fondo para la financiación de los pagos a proveedores.

Para poder participar en el FFPP el pleno de la corporación local tenía la obligación de aprobar un plan de ajuste, cuya finalidad es asegurar la sostenibilidad financiera de la operación endeudamiento.

En ese mismo año el gobierno flexibilizó los reintegros de los saldos negativos de las liquidaciones de 2008 y 2009 de la participación en tributos del Estado para aquellas entidades locales que estuvieran pendientes de reintegrar importes a la Hacienda del Estado fijando un plazo de devolución de 10 años (disposición final décima de la Ley 2/2012, de 29 de junio, de Presupuestos Generales del Estado para el año 2012). Hay que advertir que en el año 2014 se amplía con otros 10 años adicionales el plazo de reintegro ya que se permite llevar a cabo la devolución de los reintegros en 20 años (disposición adicional única del Real Decreto-ley 12/2014, de 12 de septiembre, por el que se conceden suplementos de crédito y créditos extraordinarios en el presupuesto de los Ministerios de Asuntos Exteriores y de Cooperación, de Educación, Cultura y Deporte, de Fomento y de Agricultura, Alimentación y Medio Ambiente). Por tanto, estas dos medidas permiten una mayor disponibilidad de recursos ya que se minoran los reintegros de las liquidaciones definitivas de 2008 y 2009 y se fracciona su devolución en 120/108 mensualidades (desde el 1 de enero del 2012 o 2013) con la posibilidad de ampliar otras 120 mensualidades (desde el 1 de enero de 2015).

En 2013 se implementa la segunda fase del FFPP mediante Real Decreto 4/2013 de medidas de apoyo al emprendedor y de estímulo del crecimiento y de la creación de empleo y también la tercera fase a través del Real Decreto 8/2013 de medidas urgentes contra la morosidad de las administraciones públicas y de apoyo a entidades locales con problemas financieros. La cantidad total abonada a los 123.733 proveedores de las entidades locales es de 11.595,47 millones de euros, donde destaca sobre todo la primera fase, que financia un total de 9.598,34 millones de euros (Ministerio de Hacienda y Administraciones Públicas, 2014). Esta inyección de liquidez tiene importantes consecuencias ya que se transforma la deuda comercial en deuda financiera.

A pesar de la dificultad que supone demostrar el impacto económico que tiene el FFPP, hay estudios que tratan de com- 
Figura 1

Medidas para reducir la morosidad de las administraciones públicas

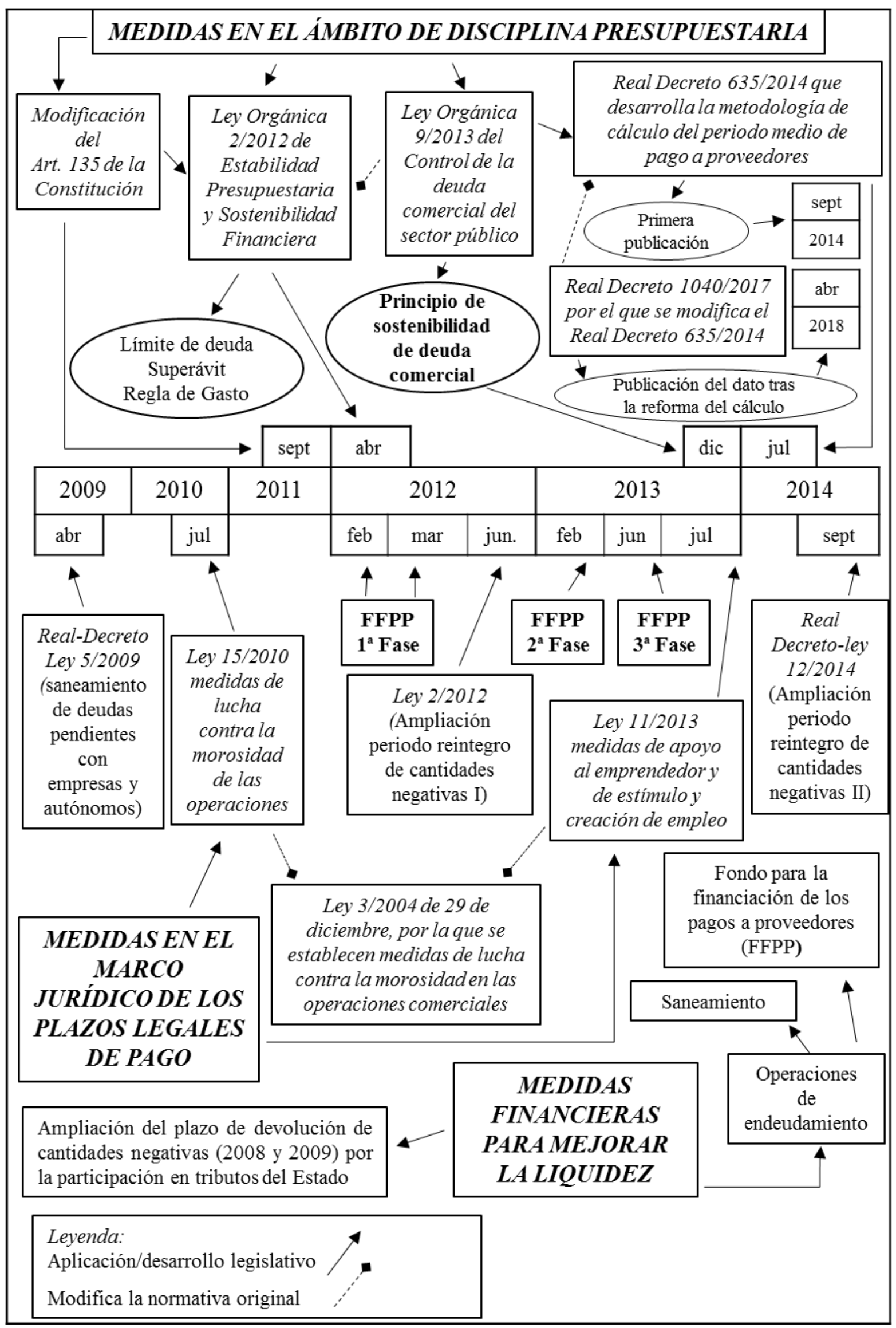


probar los efectos positivos que tiene el mismo en el PIB real o en la disminución de la tasa de desempleo (Delgado-Téllez, Hernández de Cos, Hurtado \& Pérez, 2015).

A finales de 2013 se produce una reforma importante en el marco de disciplina presupuestaria, ya que se modifica la LOEPSF con el objetivo de introducir el control fiscal de los periodos de pago en el ordenamiento jurídico español. En la exposición de motivos de la Ley Orgánica 9/2013 de control de la deuda comercial del sector público, se expresa que inicialmente la normativa de estabilidad presupuestaria de 2012 ignoró una de las expresiones más relevantes del endeudamiento: la deuda comercial. Por lo tanto, el control de los periodos de pago de las administraciones públicas resulta necesario, ya que la morosidad de la deuda comercial pone en riesgo los principios de estabilidad presupuestaria y sostenibilidad financiera, y contribuye a una mejor protección de los acreedores. A diferencia de lo que sucede con el FFPP, en virtud del cual la deuda comercial se convierte en deuda financiera, tras la aprobación del principio de sostenibilidad de deuda comercial, la deuda comercial directamente pasa a ser un elemento del sistema de disciplina fiscal (Medina, 2014).

Como consecuencia de este nuevo mecanismo de disciplina fiscal, las administraciones deben publicar periódicamente el periodo medio de pago a proveedores desde septiembre de 2014. De acuerdo con la normativa, existe sostenibilidad de la deuda comercial cuando el periodo medio de pago a proveedores no supere el plazo máximo previsto en la normativa de morosidad, que actualmente es de 30 días. Ramos (2014) señala que la deuda comercial es la morosidad de la deuda pública con los proveedores.

El cómputo de días del periodo medio de pago que difunden las administraciones públicas y que es objeto de control se calcula conforme al Real Decreto 635/2014 que desarrolla la metodología de cálculo del periodo medio de pago a proveedores, metodología que en el año 2017 fue objeto de modificación ${ }^{1}$ como consecuencia de las dudas generadas sobre su compatibilidad con la Directiva 2011/7 UE . El incumplimiento del plazo de pago a proveedores habilita al Ministerio de Hacienda y Función Pública para el establecimiento de las medidas preventivas, correctivas y coercitivas previstas en la normativa de estabilidad. Incluso permite la aplicación de las mismas medidas previstas para los supuestos de incumplimiento de déficit y deuda: no disponibilidad de créditos o asunción por el Estado de competencias normativas sobre los impuestos cedidos (Medina, 2014).

En la Figura 1 se ilustra esquemáticamente el horizonte temporal de las reformas establecidas en España, teniendo presente la orientación con la que se promulgan: medidas en el ámbito de disciplina presupuestaria, medidas en el marco jurídico de los plazos legales de pago y medidas financieras

${ }^{1}$ El Real Decreto 635/2014 estima el retraso de la deuda comercial en términos económicos. Inicialmente, para el cálculo del periodo medio de pago, esta metodología consideraba los días naturales transcurridos desde los treinta días posteriores a la fecha de anotación de la factura o registro administrativo correspondiente, según conste en el registro contable de facturas o sistema equivalente, o sino desde la fecha de aprobación de la certificación mensual de obra. Con la aprobación del Real Decreto 1040/2017 de 22 de diciembre se elimina la expresión "desde los treinta días posteriores", por lo que actualmente el plazo máximo de pago a proveedores se empieza a computar a partir de la entrada de las facturas, y no como sucedía anteriormente que se contabilizaba desde los 30 días siguientes a la entrada de las mismas. Este indicador computa los plazos de diferente manera que el periodo legal de 30 días de pago fijado en la normativa de morosidad (Ley 3/2004) o los plazos legales de pago establecidos en la Ley de Contratos del Sector Público (RDL 3/2011). Estas cifras también difieren del periodo medio de pago en términos contables que figura en la antigua Instrucción del modelo normal de contabilidad local (ORDEN EHA/ 4041 /2004). para mejorar la liquidez, que son aquellas políticas que incentivan financieramente a las administraciones públicas.

\section{Diseño de la investigación}

\subsection{Muestras y datos}

Para realizar el análisis empírico inicialmente se parte de los municipios españoles de más de 20.000 habitantes, que en total son 398 ayuntamientos (Instituto Nacional de Estadística, 2015). Se toma la cifra de 20.000 habitantes ya que es referencia del nivel mínimo de prestación de servicios públicos del artículo 26 de la Ley 7/1985, reguladora de las Bases del Régimen Local. El estudio empírico se compone de dos partes distintas:

a) Evolución del periodo medio de pago en 2009-2015. En este apartado se elaboran diferentes grupos de municipios atendiendo a si participan o no en los diferentes tipos de medidas financieras que se implantan con el objetivo de mejorar la liquidez de las entidades locales. A través de diferentes muestras, esta primera parte permite reflejar la evolución del periodo medio de pago diferenciando entre los municipios que participan en el saneamiento de deudas con empresas y autónomos de 2009, los ayuntamientos que participan en la primera fase del FFPP en 2012, aquellos municipios que participan en la segunda y tercera fase del FFPP en 2013, los ayuntamientos que se acogen a la ampliación de reintegro de cantidades negativas, los municipios que participan en al menos una de las medidas expuestas anteriormente y el grupo de municipios compuesto por aquellos que no participan en ninguna de las medidas de mejora de liquidez. Por tanto, en esta parte se consideran 377 municipios diferentes de más de 20.000 habitantes (no se incluyen los ayuntamientos de País Vasco y Navarra ya que no se pueden acoger a las medidas estudiadas).

b) Explicación del periodo medio de pago mediante la metodología de datos de panel 2009-2015. En este apartado se seleccionan los ayuntamientos de más de 20.000 habitantes que no han participado en ninguna de las tres medidas financieras citadas anteriormente: plan de saneamiento de deudas pendientes con empresas y autónomos, el FFPP y la ampliación del periodo de reintegro de cantidades negativas. Esto supone que la muestra de este grupo de entidades está compuesta por 73 ayuntamientos. Esta selección de la muestra se justifica porque como las medidas aplicadas favorecen la gestión financiera a corto plazo y benefician el periodo de pago de algunos ayuntamientos, se entiende necesario que para analizar el impacto que tiene la regla fiscal y la gestión desarrollada por cada ayuntamiento, se deben de aislar los incentivos económicos provocados por las medidas.

La variable dependiente que se utiliza es el periodo medio de pago expresado en términos contables, calculado conforme a la antigua Orden/4041/2004 que aprueba la Instrucción del modelo normal de Contabilidad Local, vigente durante la mayor parte del intervalo que se analiza. Esta magnitud contable presenta una aproximación muy realista del estudio de la deuda comercial, aunque hay que aclarar que su cálculo difiere del periodo medio de pago expresado en términos económicos regulado en el Decreto 635/2014 y que se publica desde 2014.

En relación con la primera hipótesis que analiza el impacto del principio de sostenibilidad de deuda comercial, hay que indicar que se mide de dos formas distintas. Primero se opta por incluir en dos estimaciones una dummy temporal circunscrita al periodo en el que resulta de aplicación la regla fiscal 
Tabla 1

Definición de variables y estadísticos descriptivos

\begin{tabular}{|c|c|c|c|c|c|c|c|c|}
\hline \multirow{2}{*}{ Variable } & \multirow{2}{*}{ Cálculo } & \multirow{2}{*}{ Recurso/Fuente } & \multicolumn{2}{|c|}{ Hipótesis } & \multirow{2}{*}{ Obs. } & \multirow{2}{*}{ Media } & \multirow{2}{*}{ Min. } & \multirow{2}{*}{ Max. } \\
\hline & & & $\mathrm{N}^{\circ}$ & Sentido & & & & \\
\hline $\begin{array}{l}\text { Periodo medio de pago } \\
\text { (pmp) }\end{array}$ & $\begin{array}{l}\text { (Obligaciones pendientes de pago del } \\
\text { cap. II y VI / Obligaciones reconocidas } \\
\text { netas del cap. II y VI) * } 365\end{array}$ & $\begin{array}{l}\text { Proporcionados por SIELOCAL } \\
\text { (2016b) y para el } 2015 \text { calculados } \\
\text { partir del Portal de Rendición de } \\
\text { Cuentas (2016) }\end{array}$ & --- & --- & 505 & 64,30 & 5 & 262 \\
\hline $\begin{array}{l}\text { Introducción del principio de } \\
\text { sostenibilidad de deuda } \\
\text { comercial (lim_pmp) }\end{array}$ & $\begin{array}{l}\text { Variable que analiza la eficacia del } \\
\text { límite del periodo de pago } \\
0 \rightarrow \text { De } 2009 \text { a } 2013 \\
1 \rightarrow 2014 \text { y } 2015\end{array}$ & & $\mathrm{H} 1$ & - & $\begin{array}{l}368 \\
143\end{array}$ & \multicolumn{3}{|c|}{$\begin{array}{l}64,15 \text { media pmp en } 2009-2013 \\
53,17 \text { media pmp en } 2014-2015\end{array}$} \\
\hline $\begin{array}{l}\text { Dummies temporales que } \\
\text { analizan el periodo medio de } \\
\text { pago (dummy_año) }\end{array}$ & $\begin{array}{l}\text { Dummies temporales que toman el } \\
\text { valor } 1 \text { para 2015, 2014, } 2013 \text { y } 2012\end{array}$ & & & $\begin{array}{l}2014 \rightarrow- \\
2015 \rightarrow-\end{array}$ & --- & ----- & ----- & \\
\hline $\begin{array}{l}\text { Ideología política } \\
\text { (ideolog_gob) }\end{array}$ & $\begin{array}{l}0 \rightarrow \text { Gobiernos conservadores } \\
1 \rightarrow \text { Gobiernos progresistas }\end{array}$ & $\begin{array}{l}\text { Web de la Secretaria de Estado de } \\
\text { Administraciones Públicas (2016) }\end{array}$ & $\mathrm{H} 2$ & + & $\begin{array}{l}260 \\
246\end{array}$ & \multicolumn{3}{|c|}{$\begin{array}{l}60,25 \text { media pmp conservadores } \\
68,58 \text { media pmp progresistas }\end{array}$} \\
\hline $\begin{array}{c}\text { Gobiernos en mayoría absoluta } \\
\text { o minoría (fort_gob) }\end{array}$ & $\begin{array}{l}0 \rightarrow \text { Gobiernos en coalición } \\
1 \rightarrow \text { Gobiernos en mayoría absoluta }\end{array}$ & $\begin{array}{l}\text { Web del Ministerio de Interior } \\
\text { (2016) }\end{array}$ & H3 & $+/-$ & $\begin{array}{l}223 \\
283\end{array}$ & \multicolumn{3}{|c|}{$\begin{array}{l}65,4 \text { media pmp gobiernos en } \\
\text { coalición } \\
62,9 \text { media pmp gobiernos en } \\
\text { mayoría absoluta }\end{array}$} \\
\hline $\begin{array}{l}\text { Proxy de tasa de desempleo } \\
\text { (desemp) }\end{array}$ & Población desempleada / Población & $\begin{array}{l}\text { Web del Servicio Público de } \\
\text { Empleo Estatal (2016) e Instituto } \\
\text { Nacional de Estadística (2015) }\end{array}$ & $\mathrm{H} 4$ & + & 508 & 0,0933 & 0,0333 & 0,183 \\
\hline Inmigración (inmig) & Población extranjera / Población & $\begin{array}{l}\text { Instituto Nacional de Estadística } \\
\text { (2015) }\end{array}$ & H5 & + & 511 & 0,1308 & 0,0144 & 0,5507 \\
\hline Periodo medio de cobro (pmc) & $\begin{array}{l}\text { (Derechos pendientes de cobro del cap. } \\
\text { I al cap. III / Derechos reconocidos } \\
\text { netos del cap. I al cap. III) * } 365\end{array}$ & $\begin{array}{l}\text { Web SIELOCAL (2016a) y para el } \\
2015 \text { calculados a partir del Portal } \\
\text { de Rendición de Cuentas (2016) }\end{array}$ & H6 & + & 505 & 55,89 & 2,29 & 267,53 \\
\hline Autonomía fiscal (auton_fiscal) & $\begin{array}{l}\text { (Impuestos directos + Impuestos } \\
\text { indirectos + Tasas) / Derechos } \\
\text { reconocidos netos }\end{array}$ & $\begin{array}{l}\text { Web del Ministerio de Hacienda y } \\
\text { Función Pública (2016b) }\end{array}$ & H7 & - & 511 & 0,5902 & 0,2481 & 0,8874 \\
\hline $\begin{array}{l}\text { Dependencia de las } \\
\text { subvenciones recibidas } \\
\text { (dep_sub) }\end{array}$ & $\begin{array}{l}\text { (Transferencias corrientes }+ \\
\text { Transferencias de capital) / Derechos } \\
\text { reconocidos netos }\end{array}$ & $\begin{array}{l}\text { Web del Ministerio de Hacienda y } \\
\text { Función Pública (2016b) }\end{array}$ & H8 & + & 511 & 0,3553 & 0,0519 & 0,6895 \\
\hline $\begin{array}{l}\text { Relevancia de la carga } \\
\text { financiera }\end{array}$ & $\begin{array}{l}\text { Carga financiera / Obligaciones } \\
\text { reconocidas netas }\end{array}$ & $\begin{array}{l}\text { Web del Ministerio de Hacienda y } \\
\text { Función Pública (2016b) }\end{array}$ & H9 & + & 510 & 0,0687 & 0 & 0,3723 \\
\hline
\end{tabular}

y después en otras dos estimaciones se incluyen diferentes dummies temporales para analizar el efecto del año específico. En la Tabla 1 se definen las variables que se utilizan y se presentan los estadísticos descriptivos.

\subsection{Metodología}

Respecto a la metodología, primero se efectúa un análisis exploratorio que analiza la evolución del periodo medio de pago en el periodo 2009-2015, teniendo presente si los municipios se han acogido a las diferentes medidas que pretenden reducir la morosidad.

Posteriormente, para dar respuesta a las hipótesis, se recurre a la metodología de datos de panel. Arellano \& Bover (1990) destacan algunas ventajas de los datos de panel respecto de las series temporales o de los datos de corte transversal: evitan problemas de agregación, mayor facilidad en el seguimiento individual y permiten estimar modelos que tienen en cuenta diferencias permanentes entre los individuos, aunque éstas no se observen.

Dentro de la metodología de datos de panel, hay que diferenciar los modelos de regresión estáticos (Pérez-López et al., 2014) y los modelos dinámicos (García-Sánchez et al., 2011; Navarro-Galera et al., 2016).

Como la estimación dinámica es preferible, ya que corrige la posible inconsistencia de los métodos estáticos (Arellano \& Bond, 1991), este estudio aplica el Método Generalizado de Momentos (GMM) utilizando estimaciones en diferencias y en niveles. Roodman (2009) destaca la popularidad de estas estimaciones planteadas para situaciones en las que hay pocos periodos de tiempo y muchos individuos, existe relación lineal o la variable dependiente depende de su pasado, entre otros supuestos.

En este trabajo primero se plantea el estimador en diferencias propuesto por Arellano \& Bond (1991) que permite calcular la regresión en dos etapas con variables endógenas utilizando sus diferencias (GMM-DIF 1 y GMM-DIF 2). Posteriormente, se utiliza el estimador en sistemas desarrollado por Blundell \& Bond (1998), que toma como base el trabajo de Arellano \& Bover (1995). Esta estimación contempla realizar la regresión con variables endógenas utilizando niveles y diferencias (GMM-SYS 1 y GMM-SYS 2).

La consistencia de estas estimaciones depende de la validez de sus instrumentos (Test de Sargan), de la ausencia de correlación serial de segundo orden (Test de Arellano y Bond) y de la significación conjunta de las variables (Prueba de Wald). Hay que indicar que el estimador de Blundell \& Bond (1998) fija una condición adicional al de Arellano \& Bond (1991) basada en que las primeras diferencias de las variables instrumentales no estén correlacionadas con los efectos fijos, aspecto que permite introducir más instrumentos y mejorar la eficiencia de esta estimación (Roodman, 2009).

Teniendo presente los escasos estudios que analizan los problemas de liquidez local, la metodología aplicada en este trabajo es más robusta que la aplicación de los modelos estáticos de datos de panel (Olmo et al., 2018) y se solventan las limitaciones inherentes del análisis discriminante que señalan en su trabajo Brusca \& Olmo (2018).

A continuación, se expresa la forma funcional de los modelos planteados, que difieren en la variable que analiza la eficacia del principio de sostenibilidad de deuda comercial: 
Tabla 2

Diferentes grupos de acuerdo con la participación o no en las medidas financieras que pretenden mejorar la liquidez

\begin{tabular}{|c|c|c|c|c|}
\hline $\begin{array}{l}\text { Grupos elaborados conforme } \\
\text { a la participación o no en las } \\
\text { medidas que contribuyen a } \\
\text { mejorar la liquidez }\end{array}$ & $\begin{array}{l}\text { Identificador } \\
\text { del grupo }\end{array}$ & $\begin{array}{c}\text { Municipios que } \\
\text { participan en la } \\
\text { medida }\end{array}$ & $\begin{array}{l}\text { Municipios de más } \\
\text { de } 20.000 \text { habitantes } \\
\text { para cada grupo }\end{array}$ & $\begin{array}{l}\text { Informe que } \\
\text { presentan y } \\
\text { fuente de } \\
\text { consulta }\end{array}$ \\
\hline $\begin{array}{l}\text { Saneamiento de deudas } \\
\text { pendientes de pago con } \\
\text { empresas y autónomos } \\
\text { (RDL 5/2009) }\end{array}$ & RDL_2009 & 438 municipios & $\begin{array}{c}88 \text { municipios en } \\
2009\end{array}$ & $\begin{array}{c}\text { Plan de } \\
\text { Saneamiento } \\
\\
\text { Ministerio de } \\
\text { Economía y } \\
\text { Hacienda (2009) }\end{array}$ \\
\hline \multirow{2}{*}{$\begin{array}{c}\text { Fondo para la } \\
\text { financiación de los } \\
\text { pagos a proveedores }\end{array}$} & FFPP_2012 & $\begin{array}{l}3.753 \text { municipios } \\
\text { en } 2012 \text { ( } 1^{\circ} \text { Fase) }\end{array}$ & $\begin{array}{c}267 \text { municipios en } \\
2012\end{array}$ & \multirow{3}{*}{$\begin{array}{c}\text { Plan de Ajuste } \\
\text { Ministerio de } \\
\text { Hacienda y } \\
\text { Función Pública } \\
\text { (2016a) }\end{array}$} \\
\hline & FFPP_2013 & $\begin{array}{c}14 \text { municipios } \\
\left.\text { ( } 2^{\text {a }} \text { Fase }\right) \text { y } \\
53 \text { municipios } \\
\left(3^{\circ} \text { Fase }\right) \text { en } 2013\end{array}$ & $\begin{array}{c}6 \text { municipios en } \\
2013\end{array}$ & \\
\hline $\begin{array}{l}\text { Ampliación del periodo } \\
\text { de reintegro de las } \\
\text { liquidaciones negativas } \\
\text { de } 2008 \text { y } 2009 \\
\text { (Ley } 2 / 2012 \text { y } \\
\text { RDL } 12 / 2014 \text { ) }\end{array}$ & Ley_RDL & 99 municipios & $\begin{array}{l}27 \text { municipios en } \\
2012 \text { y } 2014\end{array}$ & \\
\hline $\begin{array}{c}\text { Municipios que han } \\
\text { participado en alguna de } \\
\text { las medidas anteriores }\end{array}$ & MEDIDAS_LIQ & ------ & 304 municipios & ----- \\
\hline $\begin{array}{l}\text { Municipios que no han } \\
\text { participado en alguna } \\
\text { de las medidas }\end{array}$ & SIN_MEDIDAS_LIQ & ------- & 73 municipios & ---- \\
\hline
\end{tabular}

\section{GMM-DIF 1 y GMM-SYS 1}

$$
\begin{aligned}
\text { pmp }_{i t}= & \lambda+\beta_{0} \text { pmp }_{i, t-1}+\beta_{1} \text { lim_pmp }_{i t}+\beta_{2} \text { ideolog_gob }_{i t} \\
& +\beta_{3} \text { fort_gob }_{i t}+\beta_{4} \text { desemp }_{i t}+\beta_{5} \text { inmig }_{i t} \\
& +\beta_{6} \text { pmc }_{i t}+\beta_{7} \text { auton_fiscal } \\
& +\beta_{9} \text { carg_fin } \text { fit }_{i t}+\eta_{i}+\varepsilon_{i t} \text { dep_sub }
\end{aligned}
$$

GMM-DIF 2 y GMM-SYS 2

$$
\begin{aligned}
\mathrm{pmp}_{i t}= & \lambda+\beta_{0} \mathrm{pmp}_{i, t-1}+\beta_{1} \text { dummy_año }_{i t}+\beta_{2} \text { ideolog_gob }_{i t} \\
& +\beta_{3} \text { fort_gob }_{i t}+\beta_{4} \text { desemp }_{i t}+\beta_{5} \text { inmig }_{i t} \\
& +\beta_{6} \text { pmc }_{i t}+\beta_{7} \text { auton_fiscal }_{i t}+\beta_{8} \text { dep_sub } b_{i t} \\
& +\beta_{9} \text { carg_fin } \text { f }_{i t}+\eta_{i}+\varepsilon_{i t}
\end{aligned}
$$

En donde: $p m p_{i, t-1}$ es la variable endógena rezagada un periodo (actúa como variable explicativa), $\beta$ sería el vector de coeficientes de las variables explicativas, la denominación de las variables representa la matriz de regresores de cada una de las variables explicativas, $\lambda$ es la constante del modelo, $\eta_{i}$ es la heterogeneidad individual inobservable, $\varepsilon_{i t}$ es el error idiosincrático, $i$ significa la i-ésima unidad transversal (ayuntamiento) y $t$ es el tiempo (año).

\section{Discusión de los resultados}

\subsection{Evolución del periodo de pago de los ayuntamientos es- pañoles}

La Tabla 2 identifica los diferentes grupos de municipios que se han confeccionado tomando como referencia la participación o no en las distintas medidas financieras estudiadas en el apartado 3. Hay que destacar el elevado grado de participación en el FFPP, especialmente en la primera fase del FFPP (FFPP_2012).

De acuerdo con la información analizada se comprueba que 82 de los 88 ayuntamientos que participaron en la operación de saneamiento del año 2009 también se acogieron a alguna de las tres fases del FFPP (el 93,18\%). En consecuencia, este hecho puede denotar la insuficiencia de esta medida inicial y la necesidad de aplicar otra serie de políticas con la finalidad de controlar y reducir la morosidad de las entidades locales.

Es necesario indicar que de los 377 municipios de los que parte la muestra inicial se pueden subdividir en dos grupos de entidades: los ayuntamientos que han participado al menos en una de las medidas descritas para favorecer la liquidez (MEDIDAS_LIQ) y los municipios que no han participado en alguna de las medidas (SIN_MEDIDAS_LIQ). Por tanto, aproximadamente solamente el $20 \%$ de los ayuntamientos de más de 20.000 habitantes no se han visto en la obligación de acogerse a alguna de las medidas expuestas.

En la Figura 2 se aprecia la evolución del periodo medio de pago de los diferentes grupos de municipios establecidos en la Tabla 2.

Se observa que los ayuntamientos que presentan los periodos de pago más bajos son aquellos que no se acogieron a ninguna de las medidas para favorecer la liquidez (SIN_MEDIDAS_LIQ) y después aquellos que se vieron en la necesidad de ampliar el periodo de reintegro de cantidades negativas (Ley_RDL). Respecto a este último grupo, la posibilidad de ofrecer fraccionar el pago y ampliar el plazo de devolución de las cantidades que debían de devolver, ha per- 
Figura 2

Evolución del periodo de pago atendiendo a la participación o no en las medidas para mejorar la liquidez

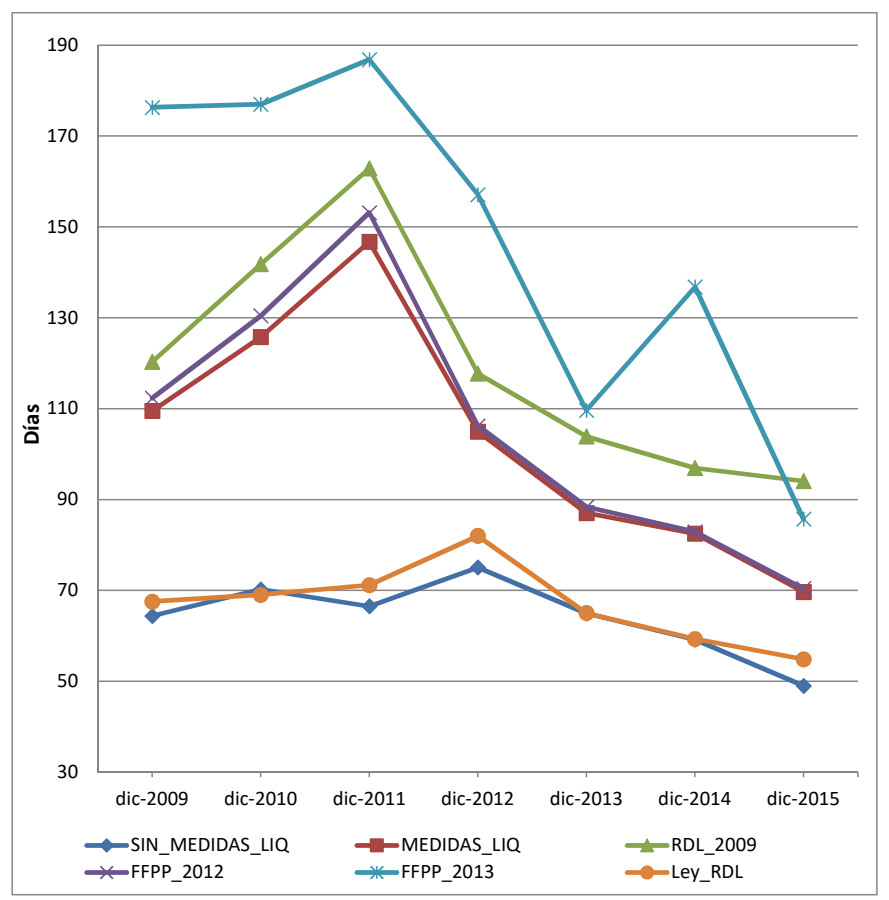

mitido que estos municipios tengan los recursos necesarios para afrontar sus obligaciones a corto plazo sin aumentar los periodos de pago. También se aprecia que se produce un incremento generalizado del periodo medio de pago hasta finales del 2011, salvo en el grupo de ayuntamientos que no habían participado en ninguna de las medidas para mejorar la liquidez (SIN_MEDIDAS_LIQ).

El efecto de la primera fase del FFPP resulta visible en la reducción del periodo de pago de los ayuntamientos que se acogieron a la misma (FFPP 2012), así como también en el grupo de ayuntamientos que han participado en alguna de las medidas analizadas (MEDIDAS_LIQ). La inyección de liquidez que otorga la primera fase del FFPP en 2012, permite experimentar a los ayuntamientos de este estrato una reducción del periodo medio de pago de alrededor de 50 días, mientras que los dos grupos de municipios con mejor posición de liquidez incrementaron ligeramente el plazo de pago en ese año.

A pesar de ser una muestra poco representativa, también hay que señalar que las entidades que participaron en el FFPP en 2013 eran las que peor situación de liquidez tenían, aunque en 2015 alcanzaron un mejor periodo de pago que el grupo de ayuntamientos que participaron en el saneamiento de deudas comerciales del año 2009.

Por último, hay que hacer mención especial a que tras introducirse en diciembre del 2013 el principio de sostenibilidad de deuda comercial y posteriormente la publicación de los periodos medios de pago en 2014, se aprecia la incidencia favorable que puede tener este nuevo mecanismo de disciplina presupuestaria en la reducción de los periodos de pago de los municipios. En este sentido, entre diciembre de 2013 y diciembre de 2015, los ayuntamientos que participaron en la primera fase del FFPP (FFPP_2012) redujeron su periodo de pago en 18 días, los que participaron en la segunda y tercera fase del FFPP (FPP_2013) lo minoraron en 24 días, las entidades que solicitaron la ampliación del periodo de reintegro (Ley_RDL) lo redujeron en 10 días y los ayuntamientos que no participaron en ninguna de las medidas pudieron reducirlo en 16 días.

\subsection{Estudio econométrico y variables explicativas del periodo medio de pago}

Antes de estimar y presentar los resultados del modelo econométrico, en la Tabla 1 se recogen los diferentes estadísticos descriptivos. En términos medios, se observa que el periodo de pago de los municipios es más elevado que el periodo de cobro, por lo que en esta comparación los ayuntamientos cuentan con un margen favorable de casi 10 días. También hay que indicar que la autonomía fiscal y las subvenciones representan el 59,02\% y el 35,53\% del total de ingresos liquidados, y la carga financiera supone un $6,87 \%$ de la liquidación del gasto. Además, se puede ver que tras la introducción del principio de sostenibilidad de deuda comercial, el periodo medio de pago de los ayuntamientos resulta inferior en el periodo 2014-2015 (53,17 respecto a 64,15 días). En relación a las variables políticas, se aprecia que los alcaldes conservadores y los gobiernos en mayoría absoluta tienden a presentar periodos de pago más reducidos.

En la Tabla 3 se reflejan los contrastes GMM que cumplen satisfactoriamente las condiciones estadísticas: Test de Sargan (no sobreidentificación de los instrumentos), Test de autocorrelación de Arellano \& Bond (correlación de primer orden y ausencia de correlación de segundo orden) y significatividad conjunta (Test de Wald). El Test de Arellano \& Bond confirma la ausencia de correlación de las primeras diferencias de las variables instrumentales y los efectos fijos. Roodman (2009) precisa que para comprobar la correlación de primer orden en niveles, es necesario atender a la correlación de segundo orden en diferencias (correlación orden 2).

En el ANEXO 1 se comprueba el bajo valor del factor de inflación de la varianza (FIV) que revela que se evitan los problemas de multicolinealidad. El ANEXO 2 recoge las correlaciones de Pearson de las variables independientes expresando en todos los casos correlaciones débiles o moderadas inferiores a 0,5. A continuación, se procede al análisis de las hipótesis que se han planteado anteriormente.

Respecto a los resultados de las estimaciones, en GMM-DIF1 y GMM-SYS-1 se constata la significatividad y signo negativo del coeficiente de la variable que correspondiente al periodo de aplicación del principio de sostenibilidad de deuda comercial (lim pmp). Igualmente, en las dummy temporales de las estimaciones GMM-DIF-2 y GMM-SYS-2 se aprecian resultados similares. Se constata que desde el año 2013 ya existía esa conciencia de reducir el periodo de pago de los ayuntamientos, aunque la dummy temporal que tiene el coeficiente más elevado es la del año 2015.

Este efecto tardío que se produce en 2015 muestra que la introducción de medidas de gestión del pago a proveedores ha requerido del tiempo oportuno para mostrar los resultados más manifiestamente, como puede ser cambios en la gestión de tesorería o de carácter organizativo. Una innovación importante que hubo en dicho año y ha potenciado la gestión en el pago a proveedores es la introducción de la factura electrónica. Otro motivo que justificaría ese efecto tardío podría deberse al periodo de adaptación de las normas, como sostiene Olmo (2018) cuando constata que tras la publicación de la LOEPSF se reduce la deuda viva pero no de forma significativa.

En línea con trabajos anteriores, los resultados demuestran que la limitación legal del periodo de pago ha sido eficaz. Kiewiet \& Szakaly (1996) evidencian la eficacia de diferentes clases de límites para los distintos tipos de deuda americana. 
Tabla 3

Estimaciones GMM para el periodo medio de pago

\begin{tabular}{|c|c|c|c|c|}
\hline \multirow{2}{*}{ VARIABLES } & \multicolumn{2}{|c|}{ DIFFERENCE GMM } & \multicolumn{2}{|c|}{ SYSTEM GMM } \\
\hline & GMM-DIF 1 & GMM-DIF 2 & GMM-SYS 1 & GMM-SYS 2 \\
\hline \multirow[t]{2}{*}{$\mathrm{pmp}(\mathrm{t}-1)$} & $0,224 * * *$ & $0,222^{* * *}$ & $0,208^{* * *}$ & $0,228^{* * *}$ \\
\hline & $(0,0249)$ & $(0,0142)$ & $(0,00822)$ & $(0,00902)$ \\
\hline lim_pmp & $\begin{array}{c}-6,288^{* * *} \\
(0,462)\end{array}$ & & $\begin{array}{c}-6,076 * * * \\
(0,466)\end{array}$ & \\
\hline dummy_2015 & & $\begin{array}{c}-11,08^{* * * *} \\
(1,616)\end{array}$ & & $\begin{array}{c}-9,269^{* * * *} \\
(1,102)\end{array}$ \\
\hline dummy_2014 & & $\begin{array}{c}-4,429 * * * \\
(1,224)\end{array}$ & & $\begin{array}{c}-6,293^{* * * *} \\
(0,892)\end{array}$ \\
\hline dummy_2013 & & $\begin{array}{c}-3,237 * * \\
(1,442)\end{array}$ & & $\begin{array}{c}-3,881^{* * * *} \\
(0,934)\end{array}$ \\
\hline dummy_2012 & & $\begin{array}{c}7,163^{* * *} \\
(1,738)\end{array}$ & & $\begin{array}{c}9,174 * * * \\
(1,206)\end{array}$ \\
\hline ideolog_gob & $\begin{array}{l}3,359^{*} \\
(1,714)\end{array}$ & $\begin{array}{l}3,926^{*} \\
(2,053)\end{array}$ & $\begin{array}{l}2,691^{* *} \\
(1,250)\end{array}$ & $\begin{array}{l}2,986^{*} \\
(1,526)\end{array}$ \\
\hline fort_gob & $\begin{array}{c}1,061 \\
(1,432)\end{array}$ & $\begin{array}{c}-1,430 \\
(1,598)\end{array}$ & $\begin{array}{c}0,530 \\
(1,000)\end{array}$ & $\begin{array}{c}-0,573 \\
(1,231)\end{array}$ \\
\hline desemp & $\begin{array}{c}502,0 * * * \\
(22,73)\end{array}$ & $\begin{array}{c}261,9^{* * *} \\
(34,59)\end{array}$ & $\begin{array}{c}306,5^{* * *} \\
(31,26)\end{array}$ & $\begin{array}{c}245,5^{* * *} \\
(28,99)\end{array}$ \\
\hline inmig & $\begin{array}{l}-20,49 \\
(26,95)\end{array}$ & $\begin{array}{c}-31,89 \\
(35,39)\end{array}$ & $\begin{array}{c}17,53 \\
(12,68)\end{array}$ & $\begin{array}{c}26,16 \\
(17,36)\end{array}$ \\
\hline pmc & $\begin{array}{l}0,227 * * * \\
(0,0218)\end{array}$ & $\begin{array}{l}0,119 * * * \\
(0,0424)\end{array}$ & $\begin{array}{l}0,160 * * * \\
(0,0189)\end{array}$ & $\begin{array}{l}0,176 * * * \\
(0,0133)\end{array}$ \\
\hline auton_fiscal & $\begin{array}{c}-23,15^{* * *} \\
(8,971)\end{array}$ & $\begin{array}{c}-23,98 * * \\
(10,34)\end{array}$ & $\begin{array}{c}-21,78 * * * \\
(4,567)\end{array}$ & $\begin{array}{c}-28,92^{* * *} \\
(6,661)\end{array}$ \\
\hline dep_sub & $\begin{array}{c}71,88^{* * *} \\
(7,904)\end{array}$ & $\begin{array}{c}62,88^{* * *} \\
(8,821)\end{array}$ & $\begin{array}{c}60,18^{* * * *} \\
(7,222)\end{array}$ & $\begin{array}{c}60,67^{* * *} \\
(7,903)\end{array}$ \\
\hline carg_fin & $\begin{array}{c}94,92^{* * *} \\
(9,344)\end{array}$ & $\begin{array}{c}81,57^{* * *} \\
(16,48)\end{array}$ & $\begin{array}{c}92,25^{* * *} \\
(16,74)\end{array}$ & $\begin{array}{c}99,89 * * * \\
(15,23)\end{array}$ \\
\hline constante & $\begin{array}{c}-27,04^{* * * *} \\
(8,764)\end{array}$ & $\begin{array}{c}8,466 \\
(11,32)\end{array}$ & $\begin{array}{c}-4,056 \\
(5,049)\end{array}$ & $\begin{array}{c}2,089 \\
(7,791)\end{array}$ \\
\hline Test de Sargan & $\begin{array}{c}\text { chi }^{2}=60,36 \\
\text { Prob }>\text { chi }^{2}= \\
=0,639\end{array}$ & $\begin{array}{c}\text { chi }^{2}=60,09 \\
\text { Prob }>\text { chi }^{2}= \\
=0,989\end{array}$ & $\begin{array}{c}\text { chi }^{2}=59,05 \\
\text { Prob }>\text { chi }^{2}= \\
=0,992\end{array}$ & $\begin{array}{c}\mathrm{chi}^{2}=58,04 \\
\text { Prob }>\text { chi }^{2}= \\
=0,997\end{array}$ \\
\hline \multicolumn{5}{|l|}{ Arellano-Bond: } \\
\hline $\begin{array}{l}\text { - Correlación } \\
\text { orden } 1\end{array}$ & $\begin{array}{c}z=-3,9 \\
\text { Prob }>z=0,0001\end{array}$ & $\begin{array}{c}\mathrm{z}=-3,6 \\
\text { Prob }>\mathrm{z}=0,0003\end{array}$ & $\begin{array}{c}z=-3,7 \\
\text { Prob }>z=0,0002\end{array}$ & $\begin{array}{c}\mathrm{z}=-3,5 \\
\text { Prob }>\mathrm{z}=0,0004\end{array}$ \\
\hline $\begin{array}{l}\text { - Correlación } \\
\text { orden } 2\end{array}$ & $\begin{array}{c}z=1,5 \\
\text { Prob }>z=0,132\end{array}$ & $\begin{array}{c}z=1,1 \\
\text { Prob }>z=0,271\end{array}$ & $\begin{array}{c}z=1,5 \\
\text { Prob }>z=0,131\end{array}$ & $\begin{array}{c}\mathrm{z}=1,1 \\
\text { Prob }>\mathrm{z}=0,261\end{array}$ \\
\hline Test de Wald & $\begin{array}{c}\text { chi }^{2}=19.422,24 \\
\text { Prob }>\text { chi }^{2}= \\
=0,000\end{array}$ & $\begin{array}{c}\text { chi }^{2}=11.789,78 \\
\text { Prob }>\text { chi }^{2}= \\
=0,000\end{array}$ & $\begin{array}{l}\text { chi }^{2}=4.959,43 \\
\text { Prob }>\text { chi }^{2}= \\
=0,000\end{array}$ & $\begin{array}{c}\text { chi }^{2}=4.135,42 \\
\text { Prob }>\text { chi }^{2}= \\
\quad=0,000\end{array}$ \\
\hline Observaciones & 358 & 358 & 432 & 432 \\
\hline $\begin{array}{l}\text { Número de } \\
\text { individuos }\end{array}$ & 73 & 73 & 73 & 73 \\
\hline
\end{tabular}

Significatividad: $* * * \mathrm{p}<0,01 ; * * \mathrm{p}<0,05 ; * \mathrm{p}<0,1$; -errores estándar entre paréntesis-

En el ámbito español, se demuestra la efectividad del límite legal de endeudamiento que figura en el TRLHL (Cabasés et al., 2007; Vallés et al., 2003,) y el impacto en la reducción de deuda de la normativa de estabilidad presupuestaria del 2001 (Benito et al., 2015). Desde otro enfoque, también se evidencia la importancia que tienen los controles internos en la gestión municipal para la reducción de deuda (Gras et al., 2014). No obstante, también hay resultados que no revelan un efecto significativo de la normativa de estabilidad del 2001 (Brusca et al., 2015a) o de los mecanismos de restricción de acceso al crédito (Vila, 2012).

Respecto a las variables políticas, se constata que los ayuntamientos gobernados por alcaldes conservadores llevan una gestión más prudente de los pagos, en cambio la fortaleza del gobierno municipal no tiene influencia en la situación financiera a corto plazo. Este resultado se ve soportado en NavarroGalera et al. (2017), los cuales aplican una regresión logística de efectos aleatorios y evidencian que los gobiernos de izquierdas tienen un mayor riesgo de impago de obligaciones financieras, mientras que la fortaleza del gobierno no es significativa. García-Sánchez et al. (2012b) encuentran que los partidos políticos de izquierdas y los gobiernos fragmentados inciden perjudicialmente en el índice de liquidez. También hay otra serie de estudios aplicados a los municipios españoles que corroboran que los partidos de izquierdas recurren más a la deuda para financiar las políticas locales (García-
Sánchez et al., 2011; Gras et al., 2014). Brusca et al. (2015b) encuentran que los partidos progresistas españoles presentan mayores niveles deuda, mientras que en el contexto local italiano la ideología política no es una variable significativa para predecir el financial distress. Rodríguez-Bolívar et al. (2018) evidencian que la ideología del partido político también importa en los niveles de sostenibilidad financiera. No obstante, hay una serie de estudios aplicados al ámbito español que demuestran que la ideología política no influye en la situación financiera municipal, en base a que las políticas de los municipios españoles están basadas en las necesidades directas de los ciudadanos, lo que supone que el factor ideológico tiene un menor impacto en las administraciones más cercanas a la ciudadanía (Bastida \& Benito, 2004; Bastida et al., 2009).

Al igual que sucede con otras dimensiones financieras, el nivel de desempleo repercute en la situación financiera a corto plazo, lo que sugiere que si el ayuntamiento se desenvuelve en un entorno socioeconómico complicado es más probable que tenga problemas de liquidez. Existe evidencia previa de que un mayor nivel de desempleo local repercute en más deuda (Feld \& Kirchgässner, 2001) y en el nivel de déficit (Vicente et al., 2013). La tasa de inmigración del municipio no afecta al periodo medio de pago de los ayuntamientos. En este mismo sentido, trabajos previos constatan que la inmigración tampoco muestra un patrón claro en la posible influencia que pudiera tener en las distintas tipologías de gasto municipal (Bastida, Guillamón \& Benito, 2013).

Respecto a las variables presupuestarias, destaca que los municipios que cobran sus derechos de crédito en menor plazo efectúan los pagos con mayor rapidez. En esta línea, los ayuntamientos con mayores retrasos en el cobro de ingresos, mayores probabilidades tenían de participar en el FFPP y de aumentar el periodo de pago a proveedores (Brusca \& Olmo, 2018). Además, un largo periodo de cobro también puede reflejar una mala gestión de cobros y/o un contexto económico difícil y perjudicial para el pago de deudas (Turley et al., 2015).

También se evidencia la relación significativa y negativa entre la autonomía fiscal y el periodo de pago, es decir, obtener una mayor liquidación de ingresos fiscales propios favorece el pago de las deudas con los proveedores. Hay que tener presente que los niveles de independencia de las autoridades locales dependen en gran medida del entorno social y económico, ya que la capacidad para generar ingresos fiscales está marcada por el nivel económico de la población local y por los impuestos aplicados a la vivienda (Zafra-Gómez et al., 2009a). García-Sánchez et al. (2012a) manifiestan que resulta favorable maniobrar con margen de independencia financiera en las situaciones de crisis. Trabajos previos encuentran que los municipios que presentan mayor autonomía fiscal (Benito \& Bastida, 2004), índice de ingresos fiscales (Pérez-López et al., 2014) o mayor recaudación impositiva (Benito et al., 2010), tienen menor necesidad de recurrir al endeudamiento. Navarro-Galera et al. (2016) encuentran que la generación de ingresos internos influye positivamente en la sostenibilidad financiera y en la capacidad financiera de la entidad local, lo que podría favorecer un incremento de la prestación de servicios públicos básicos. A este respecto, la recaudación de tasas por parte de los gobiernos locales favorece el suministro de los servicios públicos básicos y es una magnitud a considerar en la explicación del "financial distress" (Jones \& Walker, 2007).

Este resultado también se confirma con el contraste del indicador opuesto, ya que las estimaciones revelan que cuánto más dependen los ingresos locales de las transferencias de otras administraciones, más riesgo existe de incrementar el 
periodo de pago.

Guillamón et al. (2011) sostienen que las transferencias no se destinan a la reducción del endeudamiento, aunque también hay otros trabajos que evidencian que una mayor dotación de transferencias favorece la reducción de deuda (Pérez-López et al., 2013, 2014). Cohen et al. (2017) constatan que mayor cantidad de transferencias por habitante caracteriza a los municipios italianos con financial distress. Heyndels (2001) analiza el efecto que se produce por las variaciones de las transferencias y las variaciones de los ingresos propios, llegando incluso los municipios a no recortar el gasto ante disminuciones de transferencias. En el caso local español, trabajos previos también evidencian el efecto positivo que tienen las transferencias en el gasto público y el flypaper effect (Bastida et al., 2009; Bastida et al., 2013). Bastida et al. (2009) manifiestan que los ayuntamientos utilizan las transferencias como si fuera "dinero gratis" cuando comparan el impacto de las subvenciones en el gasto y en los ingresos por tasas municipales.

En definitiva, los resultados de estas dos hipótesis planteadas para la deuda comercial, en gran medida se ajustan a los hallazgos obtenidos para la deuda financiera, como sucede en el trabajo de Vicente et al. (2013) que encuentran que mayores transferencias per cápita y menores ingresos fiscales se traduce en mayor deuda.

Por último, resulta interesante demostrar la relación que existe entre la carga financiera y la situación financiera a corto plazo, ya que cuanto más elevados sean los desembolsos financieros mayor será la probabilidad de incrementar los plazos de pago. Prior et al. (2019) indican que el endeudamiento financiero impone un coste adicional en comparación con la deuda comercial, hecho que permite no incurrir en costes financieros y tener al final más recursos a disposición de los servicios públicos. Además, el hecho de que las entidades locales cumplan con el límite de pago de 30 días supone acumular menos endeudamiento (Balaguer-Coll \& IvanovaToneva, 2019). Wang et al. (2007) constatan que mejor posición de solvencia a largo plazo, dimensión en la que los pasivos financieros a largo plazo tienen una presencia muy importante, se relaciona favorablemente con la dimensión de liquidez. Gore (2009) evidencia que las ciudades americanas con mayor deuda per cápita y que reciben mayores fondos del estado presentan menores excesos de efectivo. También hay que tener en cuenta que la Constitución reconoce la prioridad absoluta en el pago de los intereses y de deuda pública, lo que podría indicar que asumir mayores compromisos en obligaciones financieras afectaría al retraso de las deudas comerciales.

\section{Conclusiones}

En España, durante el sexenio 2009-2014 se implementan diferentes tipos de políticas con el objetivo de reducir la morosidad las administraciones públicas, hecho que denota que existe un mayor interés por combatir la insolvencia del sector público.

En particular, durante este periodo se establecen varias medidas que incentivan financieramente a las entidades locales (saneamiento de deudas con empresas y autónomos, fraccionamiento de las devoluciones de cantidades negativas al Estado y el Fondo para la financiación de los pagos a proveedores) y a finales de 2013 se introduce el principio de sostenibilidad de deuda comercial, lo que se une a la reforma del marco jurídico de los plazos legales de pago de 2010 y 2013.

En este marco, este trabajo contribuye al análisis de la situación financiera a corto plazo, teniendo presente si los ayuntamientos han participado o no en las diferentes medidas financieras que tenían la finalidad de mejorar la liquidez. En este sentido, se destaca la importante reducción del periodo medio de pago de los municipios que participaron en el Fondo para la financiación de los pagos a proveedores, la disminución de los plazos de pago tras la introducción del principio de sostenibilidad de deuda comercial y que los ayuntamientos que no se vieron obligados a concertar las operaciones de endeudamiento eran los que mejores plazos de pago presentaban.

En lo que respecta al análisis empírico, se demuestra que el principio de sostenibilidad de la deuda comercial ha permitido reducir los periodos medios de pago de los ayuntamientos durante los dos primeros años de vigencia, aunque es durante el segundo año cuando se registra mayor eficacia en el control de la deuda comercial. Este efecto tardío puede ser debido a que las formas de gestión y los recursos de los ayuntamientos se ajustan gradualmente a los controles y límites impuestos por la normativa.

De todos modos, la regla fiscal ha supuesto un avance en la mejora de los plazos de pago de los ayuntamientos que no participaron en ninguna de las medidas, mientras que la situación financiera a corto plazo del resto de entidades locales también se ha visto favorecida por el propio impulso económico derivado de las medidas financieras para favorecer la liquidez y la implantación de un plan de ajuste.

Los resultados también muestran la influencia de la ideología política en la situación de liquidez de los ayuntamientos españoles, ya que los gobiernos de tendencia progresista se demoran más días en el abono de sus deudas comerciales. En cambio, la fortaleza del gobierno no es una cuestión relevante en este aspecto.

También se puede establecer cierta repercusión del entorno socioeconómico en la situación financiera a corto plazo. En concreto, la situación del mercado laboral local podría repercutir en la celeridad de pago de las deudas con los proveedores, por lo que será más beneficioso para la dimensión de liquidez de los ayuntamientos desenvolverse en territorios con bajas tasas de desempleo.

En relación a las variables financieras, se constata que el periodo medio de cobro, la autonomía fiscal, la dependencia de las subvenciones y la relevancia de la carga financiera son indicadores a considerar en la situación de financiera a corto plazo.

Los resultados de esta investigación son de gran utilidad práctica para la gestión pública, así como para el establecimiento y diseño de políticas presupuestarias, ya que de los mismos se derivan implicaciones prácticas importantes que pueden contribuir para la mejora de la gestión económica y financiera local.

Se confirma que la normativa ha favorecido el control de los periodos de pago de los municipios. En países descentralizados para intentar alcanzar la estabilidad y sostenibilidad del conjunto de las cuentas públicas es necesario implantar reglas fiscales para las entidades subnacionales. La fuente legal, el diseño de la regla fiscal, la capacidad para implantar la norma y los mecanismos de ejecución para garantizar el cumplimiento son elementos que afectan a la eficacia de las reglas subnacionales (Corbacho \& Ter-Minassian, 2013). Por lo tanto, el hecho de que el principio de sostenibilidad de deuda comercial se ampare en una ley orgánica, sea una regla fiscal numérica de fácil seguimiento, exista transparencia en la difusión periódica de los periodos de pago, se regulen importantes mecanismos de ejecución y exista el papel supervisor del Ministerio de Hacienda, son las bases iniciales que contribuyen a facilitar el control eficaz de los plazos de pago. 
Sin obviar la situación económica local, la celeridad en el cobro de los impuestos locales es un aspecto a considerar. Para facilitar la entrada de los cobros en las arcas de los ayuntamientos, Wang (2014) recomienda proveer de múltiples métodos de pago, asegurar la correcta dirección de las cuentas bancarias, establecer políticas para los pagos tardíos, centrarse en la velocidad de pago de los grandes contribuyentes y disponer de una línea directa de servicio al ciudadano.

Por ello, otra implicación importante es la necesaria elaboración periódica de un presupuesto de tesorería, como herramienta apropiada para gestionar adecuadamente la tesorería de los ayuntamientos. Una planificación realista de los diferentes cobros y pagos resulta de gran ayuda en la gestión de tesorería, sin embargo, la aparición de retrasos en los pagos de las entidades locales directamente implica una gestión de tesorería ineficaz. El análisis de las posibles desviaciones que surjan en el presupuesto de tesorería, explicar las causas que las motivan e implantar medidas correctoras al respecto podría ser de ayuda para reequilibrar la posición financiera a corto plazo. Desde un punto de vista general, habría que cuestionarse si los motivos de las demoras son resultado de la asfixiante situación de liquidez, se deben a rutinas o inercias administrativas o son consecuencia de ciertas conductas deliberadas o políticas implantadas relacionadas con las estrategias de pagos de los municipios.

De la misma manera que sucede con otras dimensiones financieras, tampoco se puede obviar la incidencia del entorno económico y del signo político. Si se prolongan las situaciones de crisis con altas tasas de desempleo quizás hubiera que plantearse establecer nuevas medidas financieras para evitar que se dispare la deuda comercial. Teniendo presente que la gestión de la tesorería no es completamente ajena a las circunstancias políticas del ayuntamiento, se recomienda analizar el comportamiento de los Ciclos Políticos Presupuestarios en la gestión de la deuda comercial y en caso de ser necesario establecer controles adicionales y limitaciones ante la posible acumulación de "facturas en los cajones" en los años electorales.

La relación positiva que hay entre la carga financiera y el periodo de pago hace prever que haya ciertos paralelismos entre la deuda financiera y la deuda comercial. En este sentido, todo indica que los municipios no sustituyen un tipo de deuda por otro, ya que las entidades con mayores niveles de carga financiera incrementan también su deuda comercial o viceversa, aquellos municipios con menos obligaciones financieras tienen menos deuda comercial. Ahora bien, la utilización de deuda comercial es un recurso más rentable que la deuda financiera, ya que como se demuestra la deuda comercial se asocia con mayores niveles de eficiencia en servicios públicos derivado de la ausencia de costes financieros (Prior et al., 2019).

Los indicadores presupuestarios podrían ser referencias útiles para las partes implicadas -legislador, interventores, políticos, Ministerio de Hacienda- que pretendan realizar o establecer un correcto seguimiento de la situación financiera a corto plazo. Si la proporción de carga financiera es elevada o incrementa de un año a otro, se sugiere realizar un análisis y control de la situación financiera a corto plazo. También se recomienda hacer un especial seguimiento en la situación de liquidez de los municipios que son más dependientes de las transferencias recibidas. El hecho que las entidades sean más dependientes implica tener menos control sobre el momento en el que dispondrán de los recursos, por lo que se ruega puntualidad y celeridad de las administraciones superiores en la transferencia de las subvenciones. Además, se confirma la idea de que cuanto más relevantes sean los ingresos tribu- tarios propios, más responsable será el ayuntamiento en la gestión a corto plazo.

Este trabajo no está exento de limitaciones. Este estudio selecciona una parte de los ayuntamientos de más de 20.000 habitantes, en consecuencia, la situación de morosidad de los pequeños municipios no ha sido analizada. Además, los municipios analizados presentan características específicas por no haber requerido la participación en ninguna de las medidas financieras para mejorar la liquidez instrumentadas por la Administración Central.

Además, este trabajo abre futuras líneas de investigación, tanto en cuanto a las entidades objeto de estudio como a las variables analizadas. En este aspecto, se propone analizar la influencia de los factores políticos y socioeconómicos en el periodo medio de pago que difunde periódicamente el Ministerio de Hacienda con su metodología de cálculo, dato que como se publica a partir de septiembre del 2014 y desde junio de 2018 con la modificación de la metodología de cálculo, no era válido para contrastar los objetivos planteados en este trabajo.

\section{Financiación}

Agradecemos la financiación del Programa de Ayudas para personal investigador predoctoral en formación financiadas por el Gobierno de Aragón y el Fondo Social Europeo (BOAOrden de 25 de agosto del 2014), así como la financiación del Gobierno de Aragón al grupo de investigación CEMBE.

\section{Conflicto de intereses}

Los autores declaran no tener nignún conflicto de intereses.

\section{Bibliografía}

Abizadeh, S., \& Gray, J.A. (1993). Provincial Government Expenditures in Canada: An Empyrical Analysis. International Review of Applied Economics, 7(1), 69-90. https://doi. org /10.1080/758528253

Advisory Commission on Intergovernmental Relations (1973). City Financial Emergencies: The Intergovernmental Dimension. Washington, DC.

Algarra, A., \& Romera, O. (2015). Una reflexión sobre los resultados obtenidos por la Administración Local en el marco de la reforma del artículo 135 de la Constitución española. Revista de Estudios de la Administración Local y Autonómica: Nueva Época, 3 (enero-junio 2015). https://revistasonline. inap.es/index.php?journal=REALA\&page $=$ article\&op $=$ view\&path\%5B\%5D=10242\&path\%5B\%5D=10751

Arellano, M., \& Bond, S. (1991). Some tests of specification for panel data: Monte Carlo evidence and an application to employment equations. The Review of Economic Studies, 58(194), 277-297. https://doi.org/10.2307/2297968

Arellano, M., \& Bover, O. (1990). La Econometría de Datos de Panel. Investigaciones económicas, 14(1), 3-45. https://www.cemfi.es// arellano/ arellano-bover-inv-econ-1990.pdf

Arellano, M., \& Bover, O. (1995). Another look at the instrumental variable estimation of error-components models. Journal of econometrics, 68(1): 29-51. https://doi.org/10. 1016/0304-4076(94)01642-d

Ashworth, J., Geys, B., \& Heyndels, B. (2005). Government Weakness and Local Public Debt Development in Flemish Mu- 
nicipalities. International Tax and Public Finance, 12(4), 395422. https://doi.org/10.1007/s10797-005-2317-3

Balaguer-Coll, M. T., \& Ivanova-Toneva, M. (2019). La importancia de los efectos espaciales en la deuda municipal. Revista de Contabilidad-Spanish Accounting Review, 22(1), 6172. https://doi.org/10.6018/rc-sar.22.1.354311

Bastida, F. J., \& Benito, B. (2005). Análisis del endeudamiento en los Ayuntamientos: un Estudio Empírico. Revista Española de Financiación y Contabilidad, 34(126), 613-635. https://doi.org/10.1080/02102412.2005.10779556

Bastida, F. J., Benito, B., \& Guillamón, M.D. (2009). An Empirical Assesment of the Municipal Financial Situation in Spain. International Public Management Journal, 12(4), 489499. https://doi.org/10.1080/10967490903328139

Bastida, F. J., Guillamón, M.D., \& Benito, B. (2013). Municipal Spending in Spain: Spatial Approach. Journal of Urban Planning and Development, 139(2), 79-93. https://doi.org/ 10.1061/(asce)up.1943-5444.0000138

Bellod, J.F. (2014). El fracaso de las Instituciones Presupuestarias en las Entidades Locales. Auditoría Pública, (63), 83-94. http://asocex.es/wp-content/uploads/PDF/ Pag\%2083-94\%20\%20n\%C2\%BA\%2063.pdf

Benito, B., \& Bastida, F.J. (2004). The Determinants of the municipal debt policy in Spain. Journal of Public Budgeting, Accounting and Financial Management, 16(4): 492-525. https: //doi.org/10.1108/jpbafm-16-04-2004-b002

Benito, B., \& Bastida, F. (2008). Política y gestión financiera municipal. Revista de Contabilidad-Spanish Accounting Review, 11(2), 43-66.

Benito, B., Bastida, F., \& Muñoz, M. J. (2010). Factores explicativos de la presión fiscal municipal. Revista de Contabilidad-Spanish Accounting Review, 13(2), 239-283. https://doi.org/10.1016/s1138-4891(10)70018-2

Benito, B., Bastida, F., \& Vicente, C. (2012). Political Budget Cycles in Local Governments. Lex Localis - Journal of Local Self-Government, 10(4). https://doi.org/10.4335/10.4335/ 10.4.341-361(2012)

Benito, B., Guillamón, M.D., \& Bastida, F.J. (2015). Nonfulfillment of debt limits in Spanish municipalities. Fiscal Studies, 36(1), 75-98. https:/ / doi.org/10.1111/j.1475-5890. 2015.12046.x

Bisogno, M., Cuadrado-Ballesteros, B., Santis, S., \& Citro, F. (2019). Budgetary solvency of Italian local governments: an assessment. International Journal of Public Sector Management, 32(2), 122-141. https://doi.org/10.1108/ IJPSM-11-2017-0328

Blundell, R., \& Bond, S. (1998). Initial conditions and moment restrictions in dynamic panel data models. Journal of econometrics, 87(1), 115-143. https://doi.org/10.1920/wp. ifs.1995.9517

Borge, L. (1995). Economic and political determinants of fee income in Norwegian Local Governments. Public Choice, 83(3-4), 353-373. https://doi.org/10.1007/bf01047752

Bowman, W., \& Calia, R. (1997). Evaluating Local Government Financial Health: Financial Indicators for Cook, DuPage, Kane, McHenry and Will Counties. The Civic Federation: Chicago. https: //www.civicfed.org/civic-federation/publications/

evaluating-local-government-financial-health-financial-indicato

Bruce, N. (1995). A fiscal federalism analysis of debt policies by sovereign regional governments. Canadian Journal of Economics, 28(special), 195-206. https://doi.org/10.2307/ 136177

Brusca, I., Labrador, M., \& Montesinos, V. (2015a). Influencia de las elecciones en la gestión de los gobiernos locales. Gestión y Política Pública, XXIV(2), 459-489. http://www.scielo.org.mx/scielo.php?script=sci/ arttext\& pid $=$ S1405-10792015000200005

Brusca, I., Manes-Rossi, F., \& Aversano, N. (2015b). Drivers for the Financial Condition of Local Government: A Comparative Study Between Italy and Spain. Lex Localis - Journal of Local Self-Government, 13(2), 161-184. https://doi.org/10. 4335/13.2.161-184(2015)

Brusca, I., \& Olmo, J. (2018). La deuda comercial de los ayuntamientos españoles: análisis empírico. Innovar, 28(70), 129-143. https://doi.org/10.15446/innovar.v28n70.74453

Cabaleiro-Casal, R., Buch-Gómez, E. J., \& Vaamonde, A. (2014). Financial situation and political parties in local governments: Empirical evidence in the Spanish municipalities. Investigaciones Europeas de Dirección y Economía de la Empresa, 20(3), 110-121. https://doi.org/10.1016/j.iedee. 2013.11.001

Cabasés, F, Pascual, P., \& Vallés, J. (2007). The effectiveness of institutional borrowing restrictions: empirical evidence from Spanish municipalities. Public Choice, 131(3-4), 293313. https://doi.org/10.1007/s11127-006-9116-y

Cohen, S., Constanzo, A., \& Manes-Rossi, F. (2017). Auditors and early signals of financial distress in Local Governments. Managerial Auditing Journal, 32(3), 234-250. https: //doi.org/10.1108/maj-05-2016-1371

Corbacho, A. \& Ter-Minassian, T. (2013). Public Financial Management Requirements for Effective Implementation of Fiscal Rules, en R. Allen, R. Hemming, y B. H., Potter, (eds.), The International Handbook of Public Financial Management, New York: Palgrave Macmillan.

Cusack, T. R. (1997). Partisan politics and public finance: Changes in public spending in the industrialized democracies, 1955-1989. Public Choice, 91 (3-4), 375-395. https://doi.org/ 10.1023/A:1004995814758

Delgado-Téllez, M., Hernández de Cos, P., Hurtado, S., \& Pérez J. J. (2015). Los mecanismos extraordinarios de pago a proveedores de las administraciones públicas en España. Documentos Ocasionales, 1501: 1-31, Madrid: Banco de España. https://www.bde.es/f/webbde/ SES/Secciones/Publicaciones/PublicacionesSeriadas/ DocumentosOcasionales/15/Fich/do1501.pdf

Donald, B., Glasmeier, A., Gray, M. \& Lobao, L. (2014). Austerity in the city: economic crisis and urban service decline?. Cambridge Journal of Regions, Economy and Society, 7, 3-15. https://doi.org/10.1093/cjres/rst040

Feld, L.P., \& Kirchgässner, G. (2001). Does Direct Democracy Reduce Public Debt? Evidence from Swiss Municipalities. Public Choice, 109(3-4), 347-370. https://doi.org/10. 2139/ssrn.1091981

Fresneda Fuentes, S., \& Hernández Borreguero, J. (2018). Institutional capacity in the accounting reform process in Spanish local governments. Revista de Contabilidad-Spanish Accounting Review, 21(2), 188-195. https://doi.org/10.1016/j. rcsar.2018.05.002

García-Sánchez, I.M., Cuadrado-Ballesteros, B., FríasAceituno, J.V., \& Mordan, N. (2012a). A new Predictor of Local Financial Distress. International of Journal of Public Administration, 35, 739-745. https://doi.org/10.1080/01900692. 2012.679173

rs-cGarcía-Sánchez, I.M., Mordán, N., \& Prado-Lorenzo, J.M. (2012b). Effect of the political system on local financial condition: Empirical evidence for Spain's largest municipalities. Public Budgeting \& Finance, 32(2), 40-68. https://doi.org/10. 1111/j.1540-5850.2011.00986.x

García-Sánchez, I. M., Prado-Lorenzo, J.M., \& CuadradoBallesteros, B. (2011). Do progressive goverments undertake different debt burdens? Partisan vs. Electoral Cycles. Revis- 
ta de Contabilidad-Spanish Accounting Review, 14(1), 29-57. https://doi.org/10.1016/s1138-4891(11)70021-8

Gardner, J. y Olden, B. (2013). Cash Management and Debt Management: Two Sides of the Same Coin. En Cangiano, M., Curristine, T. y Lazare, M. (eds.), Public Financial Management and Its Emerging Architecture, Washington, International Monetary Fund.

Gore, A. (2009). Why Do Cities Hoard Cash? Determinants and Implications of Municipal Cash Holdings?. The Accounting Review, 84(1), 183-207.

Governmental Accounting Standards Board (1999). Statement of the Governmental Accounting Standards Board Nž 34: Basic financial statements-and managementt's discussion and analysis-for state local governments. Norwalk, CT.

Gras, E., Hernández, J., \& Palacios, M. (2014). An Explanation of Local Government Debt in Spain Based on Internal Control System. Lex Localis - Journal of Local SelfGovernment, 12(4), 775-792. https://doi.org/10.4335/12.4. 775-792(2014) https://doi.org/10.2139/ssrn.913425

Groves, M., Godsey, W., \& Shulman, M. (1981). Financial Indicators for Local Government. Public Budgeting and Finance, 1(2), 42-60. https://doi.org/10.1111/1540-5850.00511

Groves, M., Godsey, W., \& Shulman, M. (2003). Evaluating Financial Condition: A Handbook of Local Local Government. 3 rd edition, ICMA, Washington.

Guillamón, M.D., Benito, B., \& Bastida, F.J. (2011). Evaluación de la deuda pública local en España. Revista Española de Financiación y Contabilidad, XL(150), 251-285. http: //dx.doi.org/10.1080/02102412.2011.10779703

Heyndels, B. (2001). Asymmetries in the flypaper effect: empirical evidence for the Flemish municipalities. Applied Economics, 33(10), 1329-1334. https://doi.org/10.1080/ 00036840122169

Instituto Nacional de Estadística (2015). Estadísticas territoriales del padrón municipal continuo. http://www.ine.es/ dynt3/inebase/es/index.html? padre $=517 \& \mathrm{dh}=1$

Jones, S., \& Walker, R.G. (2007). Explanators of Local Goverment Distress. Abacus, 43(3), 396-418. https://doi.org/ 10.1111/j.1467-6281.2007.00238.x

Kiewiet, D.R., \& Szakaly, K. (1996). Constitutional limitations on borrowing: An analysis of state bonded indebtedness. Journal of Law, Economics and Organization, 12(1), 6297. https://doi.org/10.1093/oxfordjournals.jleo.a023362

Kim, Y., \& Warner, M.E. (2016). Pragmatic municipalism: local government service delivery after the great recession. Public Administration, 94(3), 789-805. https://doi.org/10. $1111 /$ padm.12267

Kloha, P., Weissert, C.S., \& Kleine, R. (2005). Developing and testing a composite model to predict local fiscal distress. Public Administration Review, 65(3), 313-323. https: //doi.org/10.1111/j.1540-6210.2005.00456.x

Levaggi, R., \& Zanola, R. (2003). Flypaper Effect and Sluggishness: Evidence from Regional Health Expenditure in Italy. International Tax and Public Finance, 10(5), 535-547. https: //doi.org/10.1023/A:1026118222901

López-Díaz, A., \& Morán E. (2013). El nuevo paradigma europeo y constitucional del déficit y la deuda. Presupuesto y Gasto Público, (73), 49-66. ISSN 0210-5977

López-Hernández, A.M., Zafra-Gómez, J.L., \& OrtizRodríguez, D. (2012). Effects of the crisis in Spanish municipalitiest' financial condition: an empirical evidence (20052008). International Journal of Critical Accounting, 4(5/6), 631-645. https://doi.org/10.1504/ijca.2012.051457

Mabras, J. (2011). El análisis de estados financieros en el sector público: el caso de los ayuntamientos. Revista de Contabilidad y Dirección, 13, 43-60.
https://accid.org/wp-content/uploads/2018/10/El/ analisis/ de/ estados/ financieros/ en/ el/ sector/ publico./_El/_caso/_de/_los/_ayuntamientos.pdf

Medina, M. (2014). La Constitucionalización de la regla del equilibrio presupuestario: integración europea, centralización estatal. Revista de Estudios Políticos (nueva época), 165 (julio-septiembre 2014), 189-210. https://recyt.fecyt. es/index.php/RevEsPol/article/view/39417

Ministerio de Economía y Hacienda (2009). Informe de entidades locales que se han acogido al RDL/2009. http://www.hacienda.gob.es/es-ES/Areas\% 20Tematicas/Administracion\%20Electronica/OVEELL/

Paginas/Saneamiento.aspx

Ministerio de Hacienda y Administraciones Públicas (2014). Balance final del Fondo de Proveedores: $41.814 \mathrm{mi}-$ llones de euros para pagar más de ocho millones de facturas. Nota de Prensa. http:/ /laadministracionaldia.inap.es/ noticia.asp?id $=1503656$

Ministerio de Hacienda y Función Pública (2016a). Información de los planes de ajuste de las Entidades Locales. http://www.hacienda.gob.es/es-ES/CDI/ Paginas/EstabilidadPresupuestaria/InformacionCCLLs/

PlanesAjusteEELL.aspx

Ministerio de Hacienda y Función Pública (2016b). Datos presupuestarios de las entidades locales: presupuestos y liquidaciones de presupuestos de entidades locales. http://serviciostelematicosext.minhap.gob.es/sgcal/ entidadeslocales/

Ministerio del Interior (2016). Consulta de resultados electorales. http://www.infoelectoral.mir.es/infoelectoral/min/

Navarro-Galera, A., Buendía-Carrillo, D., Lara-Rubio, J., \& Rayo-Cantón, S. (2017). Do Political Factors Affect the Risk of Local Government Default? Recent Evidence from Spain. Lex Localis - Journal of Local Self-Government, 15(1), 43-66. https://doi.org/10.4335/15.1.43-66(2017)

Navarro-Galera, A., Rodríguez-Bolívar, M.P., AlcaideMuñoz, L., \& López-Subires, M.D. (2016). Measuring the financial sustainability and its influential factors in local governments. Applied Economics, 48(41), 3961- 3975. https://doi.org/10.1080/00036846.2016.1148260

Olmo, J. (2018). Explanatory factors and limitations of Spanish local debt. Academia Revista Latinoamericana de Administración, 31(2), 360-377. https://doi.org/10.1108/ arla-12-2015-0330

Olmo, J., Brusca, I., \& Labrador, M. (2018). La morosidad en el sector local español: factores de riesgo y prevención. Revista Galega de Economía, 27(1), 17-30. http://www.usc. es/econo/RGE/Vol27/rge2712.pdf

Pascual-Ezama, D., \& del Río, J. (2012). Un año de medidas contra la morosidad en las operaciones comerciales: £oxígeno para PYMES y autónomos? Auditoría Pública, (58), 85-94. http://asocex.es/ un-ano-de-medidas-contra-la-morosidad-en-las-operaciones-come

Pérez-López, G., Plata-Díaz, A.M., Zafra-Gómez, J.L., \& López-Hernández, A. M. (2013). Deuda viva municipal en un contexto de crisis económica: análisis de los factores determinantes y de las formas de gestión. Revista de ContabilidadSpanish Accounting Review, 16(2), 83-93. https://doi.org/10. 1016/j.rcsar.2012.12.001

Pérez-López, G., Plata-Díaz, A.M., Zafra-Gómez, J.L., \& López-Hernández, A. M. (2014). Operaciones fuera de presupuesto (off budget), factores políticos y deuda municipal. Gestión y Política Pública, 23(1), 185-218. http://www.scielo.org.mx/scielo.php?pid= S140510792014000100005\&script=sci/ abstract

Pérez-López, G., Prior, D., \& Zafra-Gómez, J.L. (2015). Ret- 
hinking New Public Management Delivery Forms and Efficiency: Long-Term Effects in Spanish Local Government. Journal of Public Administration Research and Theory, 25(4), 11571183. https://doi.org/10.1093/jopart/muu088

Plata-Díaz, A., Pérez-López, G., \& Zafra-Gómez, J.L. (2012). Principales tendencias en la evaluación de la condición financiera municipal y el efecto crisis management. Contaduría Universidad de Antioquia, (60), 165-178. https://aprendeenlinea.udea.edu.co/revistas/index.php/ cont/issue/view/1328/showToc

Pogue, T. F. (1970). The effect of debt limits: some new evidence. National Tax Journal, 23(1), 36-49. https://www. jstor.org/stable/41791699

Prior, D., Martín-Pinillos-Castellanos, I., Pérez-López, G., \& Zafra-Gómez (2019). Cost efficiency and financial situation of local governments in the Canary Isles during the recession. Revista de Contabilidad-Spanish Accounting Review, 22(2), 129-144.

Ramos, E. (2014). Las recientes novedades legislativas en el marco económico de las entidades locales. Presupuesto y Gasto Público, (77), 265-277. ISSN 0210-5977

Rendición de Cuentas (2016). Consulta de cuentas del 2015. http://www.rendiciondecuentas.es/es/ consultadeentidadesycuentas/buscarCuentas /

Rivenbark, W.C., Roenigk, D.J., \& Allison, G.S. (2010). Conceptualizing financial condition of Local Government. Journal of Public Budgeting, Accounting \& Financial Management, 22(2), 149-177. https://doi.org/10.1108/jpbafm-22-02-2010-b001

Rodríguez-Bolívar, M., Navarro-Galera, A., Alcaide-Muñoz, L., \& López-Subirés, M.D. (2016a). Analyzing Forces to the Financial Contribution of Local Governments to Sustainable Development. Sustainability, 8(9), 925. https://doi.org/10. 3390/su8090925

Rodríguez-Bolívar, M. P., Navarro-Galera, A., AlcaideMuñoz, L., \& López-Subirés, M. D. (2016b). Risk Factors and Drivers of Financial Sustainability in Local Government: An Empirical Study. Local Government Studies, 42(1), 29-51. https://doi.org/10.1080/03003930.2015.1061506

Rodríguez-Bolívar, M. P., Navarro-Galera, A., LópezSubirés, M. D., \& Alcaide-Muñoz, L. (2018). Analysing the accounting measurement of financial sustainability in local governments through political factors. Accounting, Auditing \& Accountability Journal, 31(8), 2135-2164. https://doi.org/ 10.1108/aaaj-10-2016-2754

Roodman, D. (2009). How to do xtabon2: An introduction to difference and system GMM in Stata. The Stata Journal, 9(1), 86-136. https://doi.org/10.1177/ $1536867 x 0900900106$

Roubini, N., \& Sachs, J. (1989). Political and economic determinants of budget deficits in the industrial democracies. European Economic Review, 33(5), 903-933. https://doi.org/ 10.1016/0014-2921(89)90002-0

Saura, J.J. (2013). Problemas prácticos (y algunas soluciones) para el endeudamiento local. Presupuesto y Gasto Público, (73), 179-195.

Secretaría de Estado de Administraciones Públicas (2016). Base de datos de Alcaldes. Elecciones 19792015. http://www.mptfp.gob.es/portal/areas/politica/ _local/sistema/_de/_informacion/_local/__SIL-/datos/ legislaturas/_1979/2015.html

Servicio Público de Empleo Estatal (2016). Datos estadísticos de paro registrado y contratos por municipios. https://www.sepe.es/contenidos/que/_es/_el/_sepe/ estadisticas/datos/ estadisticos/municipios/index.html

Sielocal (2016a). Periodo medio de cobro de los ayuntamientos. http://www.sielocal.com/informe/386/ Periodo-medio-de-cobro

Sielocal (2016b). Periodo medio de pago de los ayuntamientos. [Datos proporcionados bajo petición. 6-05-2016]

Tellier, G. (2006). Public expenditures in Canadian provinces: An empirical study of poltico-economic interactions. Public Choice, 126(3-4), 367-385. https://doi.org/10.1007/ s11127-006-2455-X

Tsebelis, G. (1995). Decision Making in Political Systems: Veto Players in Presidentialism, Parliamentarism, Multicameralism and Multipartyism. British Journal of Political Science, 25(3), 289-325. https://doi.org/10.1017/ s0007123400007225

Turley, G., Robbins, G., \& McNena, S. (2015). A Framework to Measure the Financial Performance of Local Governments. Local Government Studies, 41(3), 401-420. https://doi.org/ 10.1080/03003930.2014.991865

Vallés, J., Pascual, P., \& Cabasés, F. (2003). Endeudamiento municipal y efectividad de las restricciones institucionales de disciplina crediticia (1988-2000). Hacienda Pública Española / Review of Public Economics, 166(3), 9-47. https: //ideas.repec.org/a/hpe/journl/y2003v166i3p9-47.html

Vicente, C., Ríos, A.M., \& Guillamón, M.D. (2013). Voting behaviour and budget stability. Revista de ContabilidadSpanish Accounting Review, 16(1), 46-52. https://doi.org/10. 1016/s1138-4891(13)70005-0

Vila, J. (2012). El endeudamiento de los municipios $£$ Una cuestión de comportamiento político? Presupuesto y Gasto Público, (66), 199-216.

Wang, X. (2014). Financial Management in the Public Sector: Tools, Applications and Cases, 3 rd edition, New York: Routledge.

Wang, X., Dennis, L., \& Sen, Y. (2007). Measuring Financial Condition: A Study of U.S. States. Public Budgeting and Finance, 27(2), 1-21. https://doi.org/10.1111/j.1540-5850. 2007.00872.x

Williams, M. (2004). Government Cash Management: Good and Bad Practice, Washington, DC: World Bank Treasury.

Williams, M. (2013). Debt and Cash management", en R. Allen, R. Hemming, \& B. H., Potter, (eds.), The International Handbook of Public Financial Management, New York: Palgrave Macmillan.

Zafra-Gómez, J.L., López-Hernández, A.M., \& HernándezBastida, A. (2009a). Developing a Model to Measure Financial Condition in Local Government. The American Review of Public Administration, 39(4), 425-449. https://doi.org/10. 1177/0275074008320710

Zafra-Gómez, J.L., López-Hernández, A.M., \& HernándezBastida, A. (2009b). Developing an alert system for local governments in financial crisis. Public Money \& Management, 29(3), 175-181. https://doi.org/10.1080/ 09540960902891731

Zafra-Gómez, J.L., López-Hernández, A.M., y HernándezBastida, A. (2009c). Evaluating financial performance in local government: maximizing the benchmarking value. International Review of Administrative Sciences, 75(1), 151-167. https://doi.org/10.1177/0020852308099510 


\section{Anexo}

Anexo 1 - Test de colinealidad: factor de inflación de la varianza (FIV)

\begin{tabular}{lcc}
\hline Variable & FIF & 1/FIF \\
\hline lim_pmp & 1,13 & 0,884529 \\
ideolog_gob & 1,18 & 0,848644 \\
fort_gob & 1,14 & 0,874828 \\
desemp & 1,23 & 0,814817 \\
inmig & 1,10 & 0,905915 \\
pmc & 1,09 & 0,918088 \\
auton_fiscal & 2,11 & 0,473939 \\
dep_sub & 2,30 & 0,435041 \\
carg_fin & 1,09 & 0,916376 \\
Media FIF (VIF) & 1,37 & \\
\hline
\end{tabular}

\begin{tabular}{lcc}
\hline Variable & FIF & 1/FIF \\
\hline dummy_2015 & 1,34 & 0,743955 \\
dummy_2014 & 1,38 & 0,724357 \\
dummy_2013 & 1,38 & 0,727173 \\
dummy_2012 & 1,39 & 0,718468 \\
ideolog_gob & 1,19 & 0,842331 \\
fort_gob & 1,15 & 0,865865 \\
desemp & 1,36 & 0,73383 \\
inmig & 1,11 & 0,901795 \\
pmc & 1,10 & 0,913169 \\
auton_fiscal & 2,29 & 0,436115 \\
dep_sub & 2,31 & 0,43278 \\
carg_fin & 1,13 & 0,882063 \\
Media FIF (VIF) & 1,43 & \\
\hline
\end{tabular}

Anexo 2- Correlaciones de Spearman

\begin{tabular}{|c|c|c|c|c|c|c|c|c|c|c|c|c|}
\hline & lim_pmp & dummy_2015 & dummy_2014 & dummy_2013 & dummy_2012 & ideolog_gob & fort_gob & desemp & inmig & $\mathrm{pmc}$ & auton_fiscal & dep_sub \\
\hline lim_pmp & 1 & & & & & & & & & & & \\
\hline dummy_2015 & $0,6455 * * *$ & 1 & & & & & & & & & & \\
\hline dummy_2014 & $0,6455^{* * *}$ & $-0,1667^{* * *}$ & 1 & & & & & & & & & \\
\hline dummy_2013 & $-0,2582 * * *$ & $-0,1667^{* * *}$ & $-0,1667 * * *$ & 1 & & & & & & & & \\
\hline dummy_2012 & $-0,2582^{* * *}$ & $-0,1667 * * *$ & $-0,1667 * * *$ & $-0,1667 * * *$ & 1 & & & & & & & \\
\hline ideolog_gob & $0,0730 * * *$ & $0,1994 * * *$ & $-0,1052^{* * * *}$ & $-0,1052 * * *$ & $-0,1052 * * *$ & 1 & & & & & & \\
\hline fort_gob & $-0,1397 * * *$ & $-0,2172 * * *$ & $0,0369 *$ & 0,0369 & 0,0369 & $-0,3336 * * *$ & 1 & & & & & \\
\hline desemp & $-0,0561 * * *$ & $-0,0924 * * *$ & 0,0200 & $0,0947^{* * * *}$ & $0,1535^{* * * *}$ & 0,0145 & $0,0462 * *$ & 1 & & & & \\
\hline inmig & $-0,0764 * * *$ & $-0,0613^{* * *}$ & $-0,0374 *$ & 0,0072 & 0,0228 & $-0,1188 * * *$ & $0,0599 * *$ & $-0,2655 * * *$ & 1 & & & \\
\hline $\mathrm{pmc}$ & $-0,1568 * * *$ & $-0,1412 * * *$ & $-0,0649 * * *$ & $-0,0137$ & 0,0138 & $-0,0389 * *$ & $0,1114 * * *$ & $0,2260 * * *$ & $0,0895 * * *$ & 1 & & \\
\hline auton_fiscal & $0,2668 * * *$ & $0,1585^{* * *}$ & $0,1862 * * *$ & $0,1610 * * *$ & $-0,0893 * * *$ & $-0,1223 * * * *$ & $-0,0156$ & $-0,2048 * * *$ & $0,2444 * * *$ & $-0,0802 * * *$ & 1 & \\
\hline dep_sub & $-0,1190 * * *$ & $-0,0775^{* * * *}$ & $-0,0762 * * *$ & $-0,0807 * * *$ & $-0,2543 * * *$ & $0,2279 * * *$ & $-0,034 *$ & $0,1792 * * *$ & $-0,2978 * * *$ & 0,0073 & $-0,4756 * * *$ & 1 \\
\hline carg_fin & $0,3203 * * *$ & $0,1114^{* * *}$ & $0,3022 * * *$ & $0,1336^{* * * *}$ & $0,0346^{*}$ & $-0,0647 * * *$ & $-0,0238$ & $0,0868 * * *$ & 0,0302 & $-0,0512^{* * * *}$ & $0,0510 * \cdots *$ & $-0,2831^{* * *}$ \\
\hline
\end{tabular}

